\title{
Novel clinical biomarkers for drug-induced liver injury
}

Youhao Chen ${ }^{1}$, Shaoxing Guan ${ }^{1}$, Yanping Guan, Siyuan Tang, Yanying Zhou, Xueding Wang, Huichang Bi, Min Huang

Guangdong Provincial Key Laboratory of New Drug Design and Evaluation, School of Pharmaceutical Sciences, Sun Yat-Sen University, Guangzhou, China (Y.C., S.G., Y.G., S.T., Y.Z., X.W., H.B., M.H.)

${ }^{1}$ These authors contribute to this work equally. 


\section{Running Title: Novel clinical DILI biomarkers}

\section{Corresponding author:}

Min Huang

E-mail: huangmin@mail.sysu.edu.cn

Address: Institute of Clinical Pharmacology,

School of Pharmaceutical Sciences, Sun

Yat-Sen University, Waihuan East Road

No.132, Guangzhou Higher Education Mega

Center, Guangzhou, China

Telephone: 020-39943011
Huichang Bi

E-mail: bihchang@mail.sysu.edu.cn

Address: Institute of Clinical Pharmacology,

School of Pharmaceutical Sciences, Sun Yat-Sen University, Waihuan East Road No.132, Guangzhou Higher Education Mega

Center, Guangzhou, China

Telephone: 020-39943470

Number of text pages: 31

Number of tables: 5

Number of figures: 0

Number of references: 199

Number of words in the abstract: 142

Number of words in the introduction: 517

Number of words in the discussion: 249 


\section{List of Abbreviations:}

\begin{tabular}{|c|c|}
\hline Abbreviation & Full names \\
\hline $\mathrm{AcHz}$ & Acetyl-hydrazine \\
\hline AEDs & Antiepileptic drugs \\
\hline AILI & APAP-induced liver injury \\
\hline ALF & Acute liver failure \\
\hline ALP & Alkaline phosphatase \\
\hline ALT & Alanine aminotransferase \\
\hline APAP & Acetaminophen (or paracetamol) \\
\hline AST & Aspartate transaminase \\
\hline AUC & Area under the curve \\
\hline CAT & Catalase \\
\hline ccK18 & Caspase-cleaved K18 \\
\hline $\mathrm{C}_{\min }$ & Tough plasma concentration \\
\hline CML & Chronic myeloid leukemia \\
\hline CNS & Central nervous system \\
\hline CPIC & $\begin{array}{l}\text { Clinical Pharmacogenetics Implementation Consortium } \\
\text { Guideline }\end{array}$ \\
\hline CYP450 & Cytochromes P450 \\
\hline DILI & Drug-induced liver injury \\
\hline EGFR & Epidermal growth factor receptor \\
\hline ePCs & Ether-phosphatidylcholines \\
\hline GIST & Gastrointestinal stromal tumor \\
\hline GLDH & Glutamate dehydrogenase \\
\hline GSH & Glutathione \\
\hline GST & Glutathione S-transferase \\
\hline GWAS & Genome wide association study \\
\hline $\mathrm{HCC}$ & Hepatocellular carcinoma \\
\hline HexCer & Hexosylceramide \\
\hline HLA & Human leukocyte antigen \\
\hline HMGB1 & High mobility group box 1 protein \\
\hline HPLC-EC & $\begin{array}{l}\text { High-pressure liquid chromatography with } \\
\text { electrochemical detection }\end{array}$ \\
\hline $\mathrm{Hz}$ & Hydrazine \\
\hline IFN- $\gamma$ & Interferon-gamma \\
\hline INH & Isoniazid \\
\hline INR & International normalized ratio \\
\hline K18 & Keratin 18 \\
\hline LPCs & Lysophosphatidylcholines \\
\hline $\mathrm{mBC}$ & Metastatic breast cancer \\
\hline $\mathrm{mCRC}$ & Metastatic colorectal cancer \\
\hline MHC & Major histocompatibility complex \\
\hline MOAIs & Monoamine oxidase inhibitors \\
\hline
\end{tabular}




\begin{tabular}{ll} 
mRCC & Metastatic renal cell carcinoma \\
mtDNA & Mitochondrial DNA \\
NAPQI & N-acetyl p-benzoquinone imine \\
NAT & N-acetyltransferase \\
NQO1 & NAD (P)H: quinone oxidoreductase \\
NSAIDs & Nonsteroidal anti-inflammatory drugs \\
NSCLC & Non-small cell lung cancer \\
PBMC & Peripheral blood mononuclear cells \\
PBPK & Population-based pharmacokinetic \\
PC & Phosphatidylcholine \\
PLOG & Polymerase $\gamma$ \\
PXR & Pregnane X receptor \\
RCC & Renal cell carcinoma \\
SMX & Sulfonamide \\
SMX-HA & Hydroxylamine metabolite of Sulfonamide \\
SOD2 & Superoxide dismutase 2 \\
SSRIs & Selective serotonin reuptake inhibitors \\
TB & Tuberculosis \\
TBIL & Total bilirubin \\
TCAs & Tricyclic antidepressants \\
TKI & Tyrosine kinase inhibitor \\
TNF $\alpha$ & Tumor necrosis factor alpha \\
UGT & UDP-Glucuronosyltransferase \\
ULN & Upper limit of normal \\
VPA & Valproic acid \\
\hline &
\end{tabular}




\begin{abstract}
Drug-induced liver injury (DILI) remains a critical clinical issue and has been a treatment challenge nowadays as it was in the past. However, the traditional biomarkers or indicators are insufficient to predict the risks and outcome of patients with DILI due to its poor specificity and sensitivity. Recently, the development of high-throughput technologies, especially omics and multi-omics has sparked growing interests in identification of novel clinical DILI biomarkers, many of which also provide a mechanistic insight. Accordingly, in this mini-review, we summarize recent advances in novel clinical biomarkers for DILI prediction, diagnosis and prognosis and highlight the limitations or challenges involved in biomarker discovery or their clinical translation. Although huge work has been done, most reported biomarkers lack comprehensive information and more specific DILI biomarkers are still needed to complement the traditional biomarkers such as ALT or AST in clinical decision making.
\end{abstract}




\section{Significance Statement}

The current review outlines an overview of novel clinical biomarkers for DILI identified in clinical retrospective or prospective clinical analysis. Many of these biomarkers provides a mechanistic insight and are promising to complement the traditional DILI biomarkers. This work also highlights the limitations or challenges involved in biomarker discovery or their clinical translation. 


\section{Visual Abstract}

None 


\section{Introduction}

Drug-induced liver injury (DILI) is defined as a predictable or unpredictable adverse reaction to liver induced by drugs or other xenobiotics in either toxic dose or common use (Andrade et al., 2019). DILI is becoming a serious clinical concern with the widespread use of hepatoxic drugs including nonsteroidal anti-inflammatory drugs, central nervous system disorder drug, anti-microbials, anti-tuberculosis and target anti-tumor agents. The annual incidence of DILI in the general population was 1 to 23.80 cases in 100,000 persons around the world (de Abajo et al., 2004; Vega et al., 2017; Shen et al., 2019). Although most of DILI cases are controllable under intent management, it can lead to acute liver failure (ALF) which can be life-threatening (Chalasani et al., 2015; Stravitz and Lee, 2019).

DILI can be roughly grouped into hepatocellular, cholestatic, or mixed according to the R value defined as serum alanine aminotransferase (ALT)/ upper limit of normal (ULN) divided by serum alkaline phosphatase (ALP) /ULN (Danan and Benichou, 1993). The DILI attribution can be defined as follow: (i) hepatocellular liver injury if $R$ value $\geq 5.0$, (ii) cholestatic liver injury if $R$ value $\leq 2.0$, (iii) mixed liver injury if $\mathrm{R}$ value is 2.0 to 5.0 . DILI is a complicated process involving a series of factors such as the overload of drug or metabolites, formation of reactive metabolites and the immune status of the host (Weaver et al., 2017). Crude category according to $\mathrm{R}$ value is not delicate enough to reflect the complexity of DILI in real world.

Traditional biomarkers such as AST, ALT, ALP or total bilirubin (TBIL) have been introduced to clinic for DILI diagnosis for decades. However, the accuracy is still poor due to their limited sensitivity and specificity. For example, the elevation of transaminase can also be observed when transaminase complexes with immunoglobulins or other proteins which protect the transaminase 
from degradation in the physiological state (McGill, 2016). Based on this, the rationale of "Hy's law" is challenged where patients with AST or ALT >3-fold of the ULN and TBIL >2-fold the ULN tend to have a poor prognosis (Zimmerman, 1968; Chalasani et al., 2015). The specificity of Hy's law was only $45.7 \%$ in predicting the prognosis of ALF (Chalasani et al., 2015). Therefore, identifying appropriate biomarkers for diagnosis, prognosis and prediction of DILI remains a challenge in clinical practice.

Recently, the development of "omics" or "multi-omics" including transcriptomics, genomics, epigenomics, metabolomics and proteomics has sparked a growing interest in novel DILI biomarker discovery. Omics-based studies with high-throughput technology, on the one hand, allow for comprehensive analysis of various biomarkers, and significantly boost the efficiency of biomarker discovery. On the other hand, biomarkers from such screens also provide mechanistic insights for understanding DILI which are usually referred as mechanistic biomarkers. For example, HLA-A*0201 identified from genome wide association study (GWAS) was associated with amoxicillin-clavulanate-induced liver injury suggesting an immune-mediated mechanism (Lucena et al., 2011). Such newly added insights make it more possible for personalized medication in clinical practice. Here, we summarize recent advances in novel clinical biomarkers for DILI and highlight the limitations or challenges involved in biomarker discovery or their clinical translation. 


\section{Nonsteroidal anti-inflammatory drug-induced liver injury}

Nonsteroidal anti-inflammatory drugs (NSAIDs) belong to a class of anti-inflammatory drugs that do not contain a steroid structure. NSAIDs are reported to be well tolerated generally, but adverse effects may occur in a small proportion of patients (Nissen et al., 2016). The incidence of NSAIDassociated hepatotoxicity is estimated to be 1-23 cases per 100000 patient per year and NSAIDs were involved for 35.5\% at clinical presentation of DILI reports (Bessone, 2010; Bunchorntavakul and Reddy, 2013).

Post-market for decades, acetaminophen (APAP or paracetamol) has been widely used since it was launched in 1995 because of its safe and effective antipyretic and analgesic effects. Although APAP is safe generally under the usual therapeutic doses $(1-4 \mathrm{~g} / \mathrm{d})$, single overdose ingestion exceeded 15-25 g may cause severe liver injury (Zimmerman and Maddrey, 1995; Larson et al., 2005). In the United States, APAP overdose is the leading reason for connection to the Poison Control Centers and accounts for more than 56000 emergency room visits, 2600 hospitalizations, and 450 deaths per year due to ALF (Lee, 2004). Besides, APAP accounted for $46 \%$ of all ALF cases, which was several fold more than all prescription drugs combined (Lee, 2017). By contrast, Asia countries have a lower incidence of APAP-induced ALF because APAP is not recommended to patients with hepatitis viruses, the prevalence of which is higher in Asian countries than the West (Lee, 2017).

During the past few decades, mechanisms of APAP-induced ALF have been widely and extensively investigated. The generation of toxic metabolite $\mathrm{N}$-acetyl p-benzoquinone imine (NAPQI) by cytochromes P450 (CYP450) is the key event of APAP-induced liver injury (AILI) (Kwon et al., 2020). Glutathione (GSH) is depleted by excess NAPQI and APAP adducts are 
formulated by binding NAPQI with intracellular proteins including mitochondrial proteins (Ramachandran and Jaeschke, 2017). APAP can cause mitochondrial oxidative stress which triggers the mitochondrial permeability transition pore opening, resulting in mitochondrial damage and release of intermembrane proteins. The apoptosis-inducing related factor further triggers to DNA fragmentation and cell necrosis (McGill et al., 2012; Woolbright and Jaeschke, 2017). Newly added insights from these studies have shed new light on AILI biomarker discovery (Table 1).

\subsection{Genetic biomarkers for AILI}

Approximately $85 \%$ to $90 \%$ of APAP at therapeutic doses undergoes phase II metabolic enzymes conjugation in vivo, forming sulfated or glucuronidated metabolites which are non-toxic and further excreted through the urine (Larson, 2007). Up to 10\% of APAP undergoes phase I metabolic enzymes oxidation via the hepatic CYP pathway (especially CYP2E1) to generate the toxic and reactive intermediate NAPQI (Forrest et al., 1982). The small amount of NAPQI produced from normal doses of APAP is rapidly conjugated by GSH and excreted into the urine (Larson, 2007). NAPQI generation pathway will be favored in the case of GSH saturation or excessive CYPs activity (Yoon et al., 2016). It is well-accepted that AILI is dose-dependent. But APAP can cause liver injury even at therapeutic dose indicating that individual variations in drug disposition gene could have an impact on AILI (Kurtovic and Riordan, 2003).

UDP-Glucuronosyltransferase (UGT) is responsible for APAP detoxication and clearance. Several studies have proposed the influential effect of SNPs in UGT on the glucuronidation status of APAP which possibly explain the individual variation of AILI (Alonso et al., 2015; Court et al., 
2017). But rare studies investigated the association between genetic alterations in corresponding CYPs and AILI. Individuals carrying the CYP3A5 rs776746 A allele had a higher risk to develop ALF in APAP overdose group $(n=78)$, compared to chronic high dose group $(n=79)$ and other DILI other than APAP $(\mathrm{n}=103)$ (Court et al., 2014). Given that the metabolic enzymes play critical roles in APAP-induced ALF and reactive metabolite detoxication, APAP disposition gene SNPs are a promising source of biomarker discovery for prediction of AILI even though relevant studies are still limited at present.

MicroRNAs are short non-coding RNAs that regulate protein translation by targeting mRNA. Liver-specific microRNAs such as miR-122, have raised great interest among researchers due to its diagnostic effect of DILI (Liu et al., 2018). In the case of APAP, Philip J et.al first measured miRNAs expression level in serum from patients with APAP-induced ALF. Results showed that serum levels of miR-122 and miR-192 were higher in ALF patients compared to the healthy controls (Starkey Lewis et al., 2011), providing pioneering evidence for miRNAs as potential clinical predictive biomarkers in APAP-induced ALF. Serum level and dynamics of hsa-miR-122-5p can discriminate patients with AILI from those with no toxicity or ischemic hepatitis, another liver injury pattern different from that of APAP (Ward et al., 2014). Serum level of miR-122-5p alone or combined with miR-382-5p were both more sensitive in prediction of APAP-induced ALF compared to ALT (Vliegenthart et al., 2015). Overall, since laboratory assays for quantification of miRNAs are available, circular miRNAs are ideal biomarkers in identifying patients who are susceptible to AILI. But there are also some limitations of microRNAs as predictive biomarker. On the one hand, candidate microRNAs identified from different studies are different and only miR-122 is served as a common candidate. On the other hand, a threshold of 
miRNA level also remains to be determined.

\subsection{Non-genetic biomarkers for AILI}

\subsubsection{APAP-protein adducts}

APAP-protein adducts are released into blood during hepatocyte lysis and its concentration is much higher in APAP overdose patients compared to the therapeutic dose patients (Heard et al., 2011; Heard et al., 2016). Quantitation of APAP-protein adducts in serum by high-pressure liquid chromatography with electrochemical detection (HPLC-EC) and immunoassays have been well-established in both experimental models and clinical studies allowing clinical measurement of APAP-protein adducts (Davern et al., 2006; Khandelwal et al., 2011). Besides, different from other biomarkers, APAP-protein adducts are considered as APAP specific. The concentration of adducts in serum of overdose patients was correlated with peak AST (but not associated with bilirubin, creatinine, APAP concentration at admission, international normalized ratio for prothrombin time and APAP dose) in a population-based pharmacokinetic (PBPK) study (James et al., 2009). Similar results were also observed in other PBPK studies (James et al., 2008; Alonso et al., 2015). Most of these studies focused on the relationship between the concentration of APAP-adducts and dose or traditional markers like ALT, but failed to provide solid evidence of APAP-protein adducts in prediction of AILI. Recently, a global multi-center prospective observational study was conducted to analyze the predictive power of the initial concentration of APAP-protein adducts in APAP-induced ALF (Chiew et al., 2020). Patients with higher initial APAP-protein adduct concentration were more prone to develop hepatotoxicity compared to those with no hepatotoxicity. More importantly, a threshold of $0.58 \mathrm{nmol} / \mathrm{mL}$ APAP-protein adduct 
showed $100 \%$ sensitive and $91 \%$ specific for discriminating patients who subsequently develop AILI (Chiew et al., 2020).

\subsubsection{Hepatocyte death-related biomarkers}

Drug-induced hepatocyte death through apoptosis or necrosis leads to the release of intracellular contents. Serum level of releasing cell products such as protein, microRNA which has been discussed above are promising mechanistic biomarkers for diagnosis and prognosis of DILI.

The serum level of full-length keratin 18 (K18), a cytoskeletal protein, reflects the cell necrosis and its cleaved form caspase-cleaved K18 (ccK18) reports cell apoptosis. Besides, high mobility group box 1 protein (HMGB1) is reflective of cell necrosis. Clinical observations have associated serum level of these biomarkers to AILI. A small population-based study showed that in patients with normal ALT or international normalized ratio (INR) $(\mathrm{n}=99)$, miR-122, HMGB1, and K18 could differentiate patients who developed AILI $(n=15)$ from those that did not $(n=84)$ with a high degree of accuracy. Furthermore, these biomarkers also significantly outperformed ALT, INR and plasma APAP concentration for the prediction of subsequent ALF $(\mathrm{n}=11)$ within $8 \mathrm{~h}$ of overdose (Antoine et al., 2013). Similarly, miR-122, HMGB1, and full-length K18 were also associated with APAP-induced ALF in both derivation cohort $(\mathrm{n}=985)$ and validation cohort $(\mathrm{n}=$ 202) and a combined model of miR-122, HMGB1, and full-length $\mathrm{K} 18$ had a more sensitive predictive power than ALT alone (Dear et al., 2018). Application of such a biomarker panel could improve the efficiency of clinical decision making both in the prevention and the treatment of ALF. 


\subsubsection{Mitochondrial damage biomarkers}

Mitochondrial dysfunction is a pattern of AILI. Serum markers of mitochondrial damage, including mitochondrial DNA (mtDNA), glutamate dehydrogenase (GLDH), nuclear DNA fragment level and circulating acylcarnitines have been investigated as clinical surrogate markers capable of indicating mitochondrial lysis following hepatocyte necrosis during AILI (James et al., 2020). Peak GLDH activity, nuclear DNA fragment level as well as mtDNA were elevated in APAP overdose patients with AILI and serum level of these three biomarkers was increased in mice treated with APAP, but not in mice treated with furosemide which causes a similar pattern of centrilobular necrosis without affecting mitochondria, indicating the essential role of mitochondrial damage in AILI (McGill et al., 2012). More mitochondrial damage was also observed in patients who died of APAP-induced ALF (McGill et al., 2014). However, both mtDNA and GLDH were not identified as powerful predictors for APAP-induced ALF in other studies (Antoine et al., 2013; Dear et al., 2018). Whether mitochondrial damage markers can act as predictors in AILI is still controversial. Therefore, a combination of two or more candidate biomarkers rather than mitochondrial damage markers alone is more reasonable in stratification of patients. Compared to each biomarker alone, a multivariate model with GLDH, K18, and miR-122 was capable of accurately differentiating AILI subjects from healthy volunteers or patients with organ damage indicating that GLDH, K18, and miR-122 are unique biomarker in predicting liver injury (Llewellyn et al., 2021).

Long chain acylcarnitines are metabolized in mitochondrial and mitochondrial dysfunction can cause accumulation of circular acylcarnitines. Hence, elevation of acylcarnitines in the serum is considered to be a sign of AILI. Targeted metabolomics in children have observed a significant 
increase of acylcarnitines in the APAP overdose group $(n=62)$ compared to the therapeutic dose group $(n=187)$ and healthy subjects $(n=23)$ (Bhattacharyya et al., 2014). Inconsistently, another metabolomic study did not found acylcarnitine increases in overdose patients even though a significant elevation of acylcarnitines in APAP overdose mice was observed (McGill et al., 2014). Overall, studies on the role of acylcarnitines in AILI are limited and whether clinical measurement of circular acylcarnitines can help AILI prediction remains to be validated.

\section{Central nervous system disorder drug-induced liver injury}

\subsection{Antiepileptic drug-induced liver injury}

Central nervous system (CNS) drugs, the second most commonly implicated types with liver injury, have substantial reports in DILI rank accounting for 12.5\% among 671 drugs (Bjornsson, 2016). The subgroup of antiepileptic drugs (AEDs) gets metabolized in the liver, especially by UGT superfamily. AEDs are shown to be the important cause of DILI worldwide, with an incidence of $11 \%, 3.9 \%, 3 \%$ and $2.2 \%$ of DILI registries from India, Spain, United States and Sweden, respectively (Devarbhavi and Andrade, 2014). Majority of the AED-related hepatotoxicity are attributed to the widely-used first-generation antiepileptic drugs, such as valproic acid, phenytoin, phenobarbital, or carbamazepine while second-generation or newer antiepileptic medications (clobazam, pregabalin, levetiracetam, etc.) are less likely to cause DILI than their older counterparts.

Valproic acid (VPA) is a broad-spectrum antiepileptic drug with specific indications for partial/generalized seizures and bipolar disorders, affecting both adults and children. It is rapidly absorbed after a single dose and has a relatively high bioavailability (96\%-100\%) and protein 
binding rate (87\%-95\%) (Romoli et al., 2019). VPA is metabolized via three major pathways: glucuronidation, mitochondria $\beta$-oxidation (both have been regarded as predominant metabolic routes accounting for 50\% and 40\%, respectively) and CYP450-mediated oxidation (only 10\%) (Romoli et al., 2019). Adequate exposure to ensure antiepileptic effect and minimizing adverse reaction are confirmed as a tough plasma concentration $\left(\mathrm{C}_{\min }\right)$ of 50-100 ug/L (Vajda et al., 1978). VPA-related liver injury is well-recognized as the third most common cause of drug-induced liver fatalities reported by the World Health Organization in 1808 hepatic ADRs (Bjornsson and Olsson, 2006). Previous data available for analysis illustrated that the incidence of VPA-related liver injury is about $1 / 35,000$ adults, $1 / 500-1 / 800$ children and less than 1 in 500 in the high-risk population (Perucca, 2002; Zaccara et al., 2007). Currently, VPA has drawn most attention on biomarker discovery compared to other antiepileptic drugs such as carbamazepine (Table 2).

\subsubsection{Genetic biomarkers for VPA-induced liver injury}

Candidate gene studies have been conducted in the setting of clinical trials studying the contribution of the genetic polymorphisms of CYPs and UGTs pathways, including UGT1A6, CYP2A6, CYP2B6 and CYP2C9, which play a vital role in metabolism of VPA and have a potential impact on VPA or its metabolites exposure in patients. For example, UGT1A6 mutations might be responsible for the differences in plasma VPA concentration which results in a dosage adjustment, and might be risk factors for VPA-induced liver injury in infants (Hung et al., 2011; Guo et al., 2012; Ghodke-Puranik et al., 2013). Metabolic pathway of CYPs (CYP2A6, CYP2B6 and CYP2C9) generates hepatotoxic metabolites, such as 4-ene VPA and its $\beta$-oxidation 
metabolite 2-propyl-2,4-pentadienoic acid, which are responsible for severe hepatic microvesicular steatosis (Kesterson et al., 1984; Zhao et al., 2017). Homozygotes of CYP2C9*2 and CYP2C $9 * 3$ could reduce the oxidative biotransformation of VPA to 4-ene-VPA, 4-OH-VPA, and 5-OH-VPA (Kiang et al., 2005). In addition, compared to the WT, the serum level of 4-ene-VPA was decreased by $29 \%$ and $61 \%$ in patients carrying one and two mutated CYP2C9 alleles, respectively (Ho et al., 2003). Notably, monitoring of VPA and its hepatotoxic metabolites (such as, 4-ene VPA) in plasma can provide a great benefit for avoiding VPA-induced hepatotoxicity (Ghozzi et al., 2011; Chen et al., 2012). However, the mechanisms and underlying signaling transductions of liver injury induced by these metabolites or polymorphisms need further investigations. In addition, we still lack studies to reveal the therapeutic window for VPA with genetic feature (i.e. 50-100ug/L therapeutic window for VPA) and further studies are needed for the determination of therapeutic window of VPA among different populations.

A host of studies have elucidated that the inhibition of mitochondrial $\beta$-oxidation or fatty acid transport, and the VPA-metabolic products might contribute to its hepatotoxicity (Guo et al., 2019). Gene mutations involved in mitochondrial metabolic and oxidative stress pathway such as POLG, SOD, GSH and CAT are likely to provide mechanistic insights for VPA DILI.

POLG which codes mitochondrial DNA polymerase $\gamma(\operatorname{pol} \gamma)$ is associated with an increased risk of VPA-induced hepatotoxicity, and even fatal damage to liver cells (Saneto et al., 2010; Stewart et al., 2010; Sitarz et al., 2014), indicating a mitochondrial-dependent apoptosis to hepatocytes and providing potential biomarkers for VPA-induced liver injury. In a study involving 17 patients with suspect VPA-induced liver injury, heterozygous genetic variations in POLG (c.3708G>T/p.Q1236H and c.3428 A>G/p.E1143G) was strongly related to the hepatotoxicity 
with a $>20$-fold risk elevation (Stewart et al., 2010). When a large retrospective analysis was performed, no association was demonstrated in the VPA DILI patients (Hynynen et al., 2018), suggesting a genetic variation in the population and prospective RCT studies are still invaluable.

Glutathione S-transferases (GSTs) are critical enzymes that catalyze inactivation of various endogenous and exogenous reactive compound by GSH conjugation. Homozygous deletion of the gene comprises null GSTM1 and GSTT1 genotype, leading to deficiency in GST. GSTM1- and GSTM1-/GSTT1- genotypes were associated with elevation of $\gamma$-glutamyltransferase levels in VPA-treated patients while no significance was found with ALT or AST (Fukushima et al., 2008). Meanwhile, superoxide dismutase 2 (SOD2) polymorphism was also tested for its potential risk for liver damage, and found that SOD2 Val/Val contributed to VPA-induced liver dysfunction with an elevated $\gamma$-glutamyltransferase levels (Saruwataria et al., 2012). Furthermore, catalase (CAT) genotype was reported as a significant genetic risk factor for VPA-induced liver dysfunction, and CAT C-262T carriers exhibited an increased risk of developing abnormal hepatic function compared with the non-carriers ( $\mathrm{OR}=3.968, P=0.003$ ) (Ma et al., 2019). These findings raise the possibility that GSTs, SOD2 and CAT may be implicated in VPA -induced hepatotoxicity for their roles on the liver oxidative stress.

\subsubsection{Non-genetic biomarkers for antiepileptic drugs-induced liver injury}

Currently, with the development of multi-omics technologies, the discovery and validation of more satisfactory non-genetic biomarkers for VPA therapy-induced hepatotoxicity is further highlighted in the clinical setting. Several studies investigating the metabolic profiles of VPA-induced hepatotoxicity have been conducted to identify the specific indicators of adverse 
effects in vitro and in vivo. For example, a study presented evidence of the early diagnosis of VPA-induced liver injury associated with glycolysis, lipid and amino acid metabolism (i.e. glucose, acetoacetate, lactate, phosphatidylcholines, amino acids, lysophosphatidylcholines, creatine, $\mathrm{N}$-acetyl glycoprotein, choline, uric acid and pyruvate) (Huo et al., 2014). Another metabolic profiling study elucidated that VPA induced alterations in oxidative stress and branched chain amino acid metabolism (Price et al., 2011). Accordingly, several metabolomic studies found that lipid transport/fatty acid in HepG2 cells, hippuric acid in rat urine and disrupted glycine in serum could serve as metabolic biomarkers for VPA -induced liver injury (Lee et al., 2009; Ji et al., 2010; Sun et al., 2010).

Lipid metabolism disruption was proposed to be a key event in VPA-treated patients and several lipidomic studies have already identified lipid biomarkers for VPA-induced liver injury. Un-targeted lipidomics analysis revealed that LPCs, Cers and SMs decreased markedly in patients with abnormal liver function (Sun et al., 2010), in which peroxime proliferators-activated receptor pathway played an essential role in activating the uptake of long-chain fatty acid and TAG synthesis. The details of lipid dysmetabolism were described and metabolite molecules, such as phosphorylcholine, sphingomyelin, triglyceride, phenolic phthiocerol, ceramides, as well as

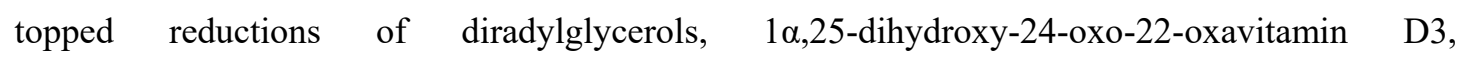
phosphoethanolamines, dolichyl-4 phosphate, 2-deoxy-20-hydroxy-5alpha-ecdysone 3-acetate were also identified as potential biomarkers in epileptic patients with VPA-induced dyslipidemia (Li et al., 2019). In addition, lipidomics analysis in rodents with VPA-induced hepatotoxicity found compelling evidence that ether-phosphatidylcholines (ePCs) were altered significantly in the liver and plasma though receiving a low dose level (Goda et al., 2018). Overall, current 
comprehensive information on effective biomarkers for VPA-induced hepatotoxicity still lack. Further validation studies should be conducted to confirm these results.

\subsection{Antidepressant drug-induced liver injury}

The prevalence of antidepressant usage increases with years worldwide. Almost all antidepressants can trigger hepatotoxicity, even under a therapeutic dose. Such injuries are usually unpredictable, idiosyncratic, dosage unrelated and generally occur as early as within a few days or up to 6 months after initial drug administration (de Gage et al., 2018). Antidepressant-induced liver injuries have been reported 5\% and 4\% of cases in Spanish registry and DILIN (Andrade et al., 2005), respectively. A cross-sectional analysis of the cases reported in a registry $(n=387)$ presented that hepatotoxicity induced by antidepressants constituted 5\% of all cases. The traditional antidepressants, such as tricyclic antidepressants (TCAs) and monoamine oxidase inhibitors (MOAIs), have higher risk for DILI than the next generation counterparts (Spigset et al., 2003). Selective serotonin reuptake inhibitors (SSRIs), the second-generation antidepressants, accounted for the incidence of SSRIs-induced liver injury of 4/100,000 patient-years (Voican et al., 2014). Life-threatening or severe DILIs has been reported for duloxetine, bupropion, trazodone, venlafaxine, nefazodone, etc (Voican et al., 2014).

Antidepressant-induced liver injury is generally hepatocellular, and less frequently cholestatic or mixed. Regarding the mechanisms for antidepressant-induced liver injury, immune-allergy or reactive metabolite formation was usually considered as the main pathophysiology (Voican et al., 2014). A major concern regarding of risk factors is dependent primarily on CYPs pathway, because the antidepressant drugs are mainly metabolized in liver by CYP system. Antidepressant-induced liver injury is generally deemed to follow a dose-independent pattern 
(Voican et al., 2014; Vukotic et al., 2021). However, inter-individual variabilities of antidepressant drugs in treatment response and adverse effect have been related to the variability of tricyclic or corresponding metabolites concentration in plasma, and thereby potentially increasing the risk of liver injury (Rudorfer and Potter, 1999).

Amitriptyline, a commonly used tricyclic antidepressant with tertiary amines, exerts both the antidepressant and antinociceptive activities due to, but not exclusively, its ability to combine with serotonin and noradrenaline at central sites (Mico et al., 2006). Liver test abnormalities occurred in $10 \%-12 \%$ of patients who administered amitriptyline. A high administration dose of amitriptyline and prolonged exposure can cause steatosis (Sahini et al., 2014), but the patho-mechanism to liver damage is still incompletely understood. It is assumed that the toxic metabolites of amitriptyline result in hepatotoxicity (Wen et al., 2008). Amitriptyline is mainly metabolized by CYP2C19 to desmethyl-metabolites, including nortriptyline which is also regarded as secondary amines. And then both the amitriptyline and its desmethyl-metabolites are metabolized by CYP2C6 to 10-hydroxy metabolites with low activity. There is substantial information relating CYP2C19 and CYP2D6 genotypes to phenotypic variability in tricyclic pharmacokinetic profiles and side effects. Clinical Pharmacogenetics Implementation Consortium Guideline (CPIC) (Hicks et al., 2017) published dosing recommendations for tricyclic antidepressants based on CYP2C19 and CYP2D6 genotypes, in which patients were assigned as ultrarapid metabolizers, normal metabolizer, intermediate metabolizer and poor metabolizer determined by theirs CYP2D6, CYP2C19 genotypes alone or combination. It is noted that CYP2D6 poor metabolizers exhibited higher than expected plasma concentrations at usual dosage. The FDA-approved drug label for amitriptyline recommended that monitoring of plasma 
concentration is necessary whenever it is going to be co-administered with an inhibitor of

\section{CYP2D6}

[https://www.accessdata.fda.gov/drugsatfda_docs/label/2014/085966s095,085969s084,085968s09

6,085971s075,085967s076,085970s072lbl.pdf;https://www.ncbi.nlm.nih.gov/books/NBK425165/].

However, whether CYP2C19 and CYP2D6 are specific to DILI is still unknown.

Regarding the results from metabolomics studies, lysophosphatidylcholines (LPCs) (16:1, 18:1, 18:2, and 20:4) and 42:1 hexosylceramide (HexCer) could be served as biomarkers by analyzing the molecules separating control rats and rats with amitriptyline-induced hepatotoxicity (Saito et al., 2014). Another study was conducted to describe the spatial abundances of lipids and bile acids in amitriptyline treated rat livers, as a result, several lipids were found to be upregulated and nine of them were classified as distinct phosphatidylcholine (PC) species illustrating phospholipidosis (Kampa et al., 2020). The useful genetic or non-genetic biomarkers for amitriptyline-induced hepatotoxicity are poorly known and have not been validated in depressant patients.

So far, no genetic polymorphisms related with greater susceptibility to idiosyncratic DILI from antidepressant drugs have been depicted. More efforts have to be made in the research of anti-depressant drug-induced liver injury.

\section{Antimicrobial-induced liver injury}

Antimicrobials are the one of most common types of drugs leading to liver injury with an incidence of $20 \%-40 \%$ of all drugs that cause DILI in western countries (Sgro et al., 2002; Bjornsson et al., 2013; Chalasani et al., 2015). In a recent retrospective study of 46,266 cases for the assessment of causality of idiosyncratic DILI, amoxicillin-clavulanic combination is the most 
leading cause of DILI (Shen et al., 2019). Different from the West, according to a recent study conducted in mainland China, the proportion of antimicrobial-induced liver injury in China is 6.08\%, ranking fourth among all the implicated DILI drug classes (Teschke, 2019). Anti-microbial-induced liver injury is normally mild and moderate but it can also lead to severe consequences such as liver-related death or ALF which needs liver transplantation. The reason why antimicrobials are so prone to DILI is still not fully elucidated. Several retrospective studies have found that antimicrobials are the main cause of idiosyncratic DILI which develops within several weeks after treatment due to metabolic or and immuno-allergic drug reaction (Garcia-Cortes et al., 2011; Teschke, 2019; Teschke and Danan, 2020). These studies indicate that pathways involving the generation of immunoreactive intermediate metabolite or host immune response are possibly the main mechanism of antimicrobial-induced liver injury. Biomarkers participating in generation of immune reactive compound like NATs polymorphisms or immune allergic pathway like HLA polymorphisms are promising to predict the risk of antimicrobial-induced hepatotoxicity (Table 3).

\subsection{Genetic markers for antimicrobial-induced liver injury}

Antimicrobials-induced liver injury is usually considered idiosyncratic for the reason that it usually occurs in the recommended dosage and thus dose-unrelated. However, researches shown that idiosyncratic DILI could be dose-dependent. Higher daily dose of oral prescription medication and longer duration of exposure were associated with higher risk of idiosyncratic liver injury (Lammert et al., 2008). These observations suggest that polymorphisms in drug metabolism enzymes or transporters have an effect on the risk of anti-microbial induced liver injury. 
Sulfonamide (SMX) is a common cause of hypersensitivity related hepatotoxicity which is attributed to its hydroxylamine metabolite (SMX-HA) (Cribb et al., 1991; Cribb and Spielberg, 1992). SMX-HA can undergo an autoxidation and become a hyperreactive derivative. One of the main detoxication pathways of sulfonamide is the $\mathrm{N}$-acetylation by $\mathrm{N}$-acetyltransferases (NATs), leading to the generation of an inactive form of the patent drug and further excretion though urine. Patients carrying SNPs in NAT2 leading to a slow phenotype of N-acetylation are more likely to develop sulfonamide-induced hepatotoxicity. In a study from Poland, NAT2 slow acetylator genotype NAT*5 $(481 \mathrm{C}>\mathrm{T})$ was found related to cotrimoxazole associated idiosyncratic reactions in 20 infants (Zielinska et al., 1998). Besides, in another study of 18 patients developing sulfonamide induced toxic epidermal necrolysis and Stevens-Johnson syndrome, 17 were identified as slow acetylator genotype (NAT2*5, *6, *7) (Wolkenstein et al., 1995). Conversely, no association of NAT2 coding alleles with sulfonamide hypersensitivity was observed in another study of 99 Caucasian adults (Sacco et al., 2012). Association between NAT2 SNPs and sulfonamide-induced hepatotoxicity needs further validation.

Apart from metabolic pathways, immunological responses of the host also play an important part in idiosyncratic hepatotoxicity which is a complex procedure involving numbers of factors and multiple steps. Human leukocyte antigen (HLA) molecules are crucial proteins in antigen presentation, the initial process of the adaptive immune system which regulates the immune response. HLA class I molecules (HLA I) present endogenous peptides processed in the proteasomes while HLA class II molecules can grasp peptides outside the cell. HLA genotype has been reported to be associated with idiosyncratic liver injury of several types of drugs including antimicrobials (Grove and Aithal, 2015). A pioneering study in Belgium $(\mathrm{n}=39)$ first 
reported the strong association between HLA-DRB1*15:01-DRB1*01:01-DQB1*06:02 haplotype and amoxicillin-clavulanate-induced cholestatic or mixed hepatitis (Hautekeete et al., 1999). Another independent association was observed between HLA-A*0201 and amoxicillin-clavulanate-induced liver injury in a GWA study of 201white European and US cases and 532 matched controls. More importantly, HLA-A*0201 was highly associated with DQB1*06:02 located in HLA II genotyping in 177 cases and 219 controls, suggesting that both HLA I and II genotype contribute to the susceptivity of amoxicillin-clavulanate-induced liver injury (Lucena et al., 2011). HLA-B*57:01 was related to flucloxacillin DILI in an GWA study of in 51 cases with flucloxacillin DILI and 60 controls and this association was repeated in another 23 cases, first providing insights for flucloxacillin-induced hepatotoxicity (Daly et al., 2009). Several GWA studies proved repeatedly that HLA-B*57:01 was the major genetic risk factor specific to flucloxacillin with no association found in other isoxazolyl penicillins or amoxicillin (Nicoletti et al., 2019).

Pregnane $\mathrm{X}$ receptor (PXR) is the key modulator of drug metabolism by regulating multiple metabolic enzymes in the liver. Numerous studies have illustrated that how PXR functions in DILI (Wang et al., 2020). Flucloxacillin is a PXR agonist and PXR polymorphism rs3814055 C >T was associated with flucloxacillin-induce liver injury in 51 flucloxacillin DILI cases, 64 flucloxacillin controls and 90 community controls (Andrews et al., 2010).

Similar as APAP, studies have identified several circulating hepato-specific microRNAs as the predictive biomarkers for DILI such as miR-122 (Kagawa et al., 2018). A multi-omics research from Korea found that miR-122 level was elevated prior to and correlated to the increase of ALT level in 32 healthy volunteers received amoxicillin-clavulanate suggesting that miR-122 could be 
a better biomarker than the traditional serum marker ALT (Lee et al., 2017). Disappointedly, patient-based studies focusing on the relation between microRNA and anti-microbial DILI still lack.

\subsection{Non-genetic biomarkers for antimicrobial-induced liver injury}

Given that HLA genotype is proposed to be associated with amoxicillin-clavulanate and flucloxacillin-induced liver injury, it is reasonable that further immune response should be activated in patients carried specific HLA mutations when the antigen presentation process is completed. Lymphocytes from patients developing amoxicillin-clavulanate-induced liver injury were able to proliferate and/or secrete interferon-gamma (IFN-Y). And interestingly, both amoxicillin-responsive and clavulanate-responsive $\mathrm{CD} 4^{+}$or $\mathrm{CD} 8^{+}$clones from patients with or without risk alleles could secrete certain immune mediators such as IFN- $\mathrm{\gamma}$, suggesting that both amoxicillin and clavulanate are responsible for DILI rather than clavulanate alone (Kim et al., 2015). Likewise, $\mathrm{CD} 4^{+}$and $\mathrm{CD} 8^{+} \mathrm{T}$ cells isolated from patients with flucloxacillin live injury are responsive to flucloxacillin. Besides, flucloxacillin responsive $\mathrm{CD} 8^{+}$cells could be stimulated to proliferate only by antigen presenting cells expressing either HLA-B*57:01 or the structurally related HLA-B*58:01 which explained the immune rationale of the genetic association of flucloxacillin (Monshi et al., 2013). However, these studies are exploratory and based on a few cases with DILI. Whether the T cell profile is significantly different between patients developing DILI and not developing DILI is poorly defined. Given that antimicrobial-induced liver injury develop within a few weeks after treatment and delayed liver injury is also observed, identification and characterization of drug-responsive $\mathrm{T}$ cell at early treatment stage could be a promising 
diagnosis biomarker for antimicrobial-induced immune allergic hepatotoxicity in a way.

\section{Anti-tuberculosis (TB) drug-induced liver injury}

The most frequent adverse event of anti-TB agents is hepatotoxicity. About $7.9 \%$ of patients receiving first-line anti-TB therapy develop treatment-related liver injury characterized by the elevation of serum level of ALT and/or AST and hyperbilirubinemia (Molla et al., 2021). In China, anti-TB agent are also the second leading cause of liver injury in China accounting for $21.99 \%$ of all cases (Shen et al., 2019). In addition, anti-TB treatment-related liver injury can interrupt patients' adherence to the regiment contributing to relapse or drug resistance. Standard treatment of tuberculosis at present is the 6-month rifampicin-based therapy containing with a 2-month regimen containing isoniazid, rifampicin, pyrazinamide, and ethambutol followed by a 4-month regimen containing isoniazid and rifampicin according to WHO guideline (World Health Organization, 2017). Among the first-line anti-TB agents, isoniazid, rifampicin and pyrazinamide are considered potentially hepatotoxic while no hepatotoxicity has been described for ethambutol (Tostmann et al., 2008). Mechanism under isoniazid-induced liver injury is well-documented which is associated with the generation of the toxic metabolite of the parent drug while the reason for rifampicin- and pyrazinamide-induced liver injury are under investigation (Table 4).

\subsection{Genetic biomarkers for anti-TB drug-induced liver injury}

Isoniazid (INH) is metabolized both by phase I and phase II enzymes. INH itself and its two metabolites, hydrazine $(\mathrm{Hz})$ and acetyl-hydrazine $(\mathrm{AcHz})$ are considered as hepatotoxic and therefore contribute to liver injury. In liver, INH undergoes hydrolysis by CYPs or acetylation by 
NAT2 and is transformed into acetyl-INH and $\mathrm{Hz}$ respectively. $\mathrm{Hz}$ can be further hydrolyzed, generating another hepatotoxic metabolite $\mathrm{AcHz}$ which is detoxicated through a second acetylation by NAT2 (Wang et al., 2016).

Acetylation rate in liver is determined by a pair of alleles of NAT2 and individuals can be divided into rapid acetylators and slow acetylators based on their haplotype of NAT. Up to date, there are 40 SNPs in NAT2 locus reported among which NAT2 $* 5, * 6$ and $* 7$ are regarded as clinically important for INH since they greatly reduce the activity of NAT2 enzyme compared to the reference allele NAT2*4 (Andrade et al., 2009; Hein and Millner, 2021). Individuals carrying any two of the mutants are slow acetylators. And more importantly, the frequencies of these alleles vary remarkably among different races with approximately 44, 26 and $1 \%$ of Caucasian population carry NAT2 $* 5, * 6$ and $* 7$ respectively in while $6,31,11 \%$ in Chinese population (Lin et al., 1994; Xie et al., 1997). Area under the curve (AUC) of Ac-Hz was 1.7-fold higher in slow acetylators, suggesting that slow acetylators are more susceptible to develop INH-induced liver injury (Lauterburg et al., 1985). The first study on the association between NAT2 polymorphisms and INH-induced hepatotoxicity was carried in 224 Chinese tuberculosis patients and showed that patients carrying two NAT2 mutants (slow acetylator) had higher risk to develop INH-induced hepatitis $(26.4 \%$ vs. $11.1 \%, P=0.013)$. Compared with rapid acetylators, slow acetylators were more likely to have severe liver injury characterized as a higher incidence to have 3 times of ULN of serum ALT when rechallenged with INH. (Huang et al., 2002). In Japanese population, the association of NAT2*6A and anti-TB-induced hepatotoxicity was observed but no relation was found between NAT2*7B and hepatotoxicity (Higuchi et al., 2007). Similar results were also reported in Southwestern Indian (Singh et al., 2009) and Brazilian population (Santos et al., 2013). 
Two independent studies on dose optimization of INH based on NAT genotyping in Japanese and Korean population proved the rationale of a dose reduction in slow acetylators in East Asian population (Azuma et al., 2013; Yoo et al., 2021). However, in a diverse population-based study, no significant association was observed between NAT2 polymorphism and INH-induced liver injury (Yamada et al., 2009).

Another possible detoxication pathway of INH-derived reactive metabolite is glutathione conjugation to $\mathrm{Hz}$ or Ac-Hz by GSTs even if the conjugation form has not been identified (Boelsterli and Lee, 2014). Higher serum level of Hz was observed not only in NAT2 slow acetylators but also in patients carried GSTM null genotype indicating that $\mathrm{Hz}$ tend to accumulate in GSTM null carriers thus contributing to hepatotoxicity (Fukino et al., 2008). At present, there are four main classes of GSTs, alpha (A), mu (M), pi (P) and theta (T) among which the expression of GSTs T1 and M1 are polymorphic. Complete loss of GSTT1 (null genotype) occur in 57\%, 20\% and 22\% and in Chinese, Caucasian and African American population respectively while 58\%, 53\% and 21\% for GSTM1 null genotype in those races (Ginsberg et al., 2009). The homozygous null GSTM1 genotype was predisposed to anti-TB-induced hepatotoxicity in 33 Indian patients (Roy et al., 2001). Furthermore, GSTM1 but not GSTT1 null genotype were found to significantly increase the risk of hepatotoxicity in sub-category of anti-TB drugs in Chinese population (adjusted OR: 2.47, 95\% C.I.: 1.13-5.39, $P=0.02$ ) (Huang et al., 2007). In addition, GSTT1 null carriers showed higher risk of anti-TB DILI in small Brazilian population $(n=43)$ (Santos et al., 2019).

Different from NAT2 and GSTs which are responsible for detoxication of INH or its toxic metabolites, CYP2E1 is involved in the generation of Ac-Hz thorough hydrolyzation of Ac-INH 
which confers liver toxicity. Individuals homozygous for CYP2E1 $\mathrm{c} 1 / \mathrm{c} 1$ have higher enzyme activity than those with one or two CYP2E1 c2 alleles (Huang et al., 2003). A number of studies have investigated the role of CYP2E1 genotype in INH-induced hepatotoxicity whereas the results remain in controversy. CYP2E1 c1/c1 genotype was first reported associated with higher risk of INH-induced liver injury compared with $\mathrm{c} 1 / \mathrm{c} 2$ or $\mathrm{c} 2 / \mathrm{c} 2$ genotype in $318 \mathrm{~TB}$ Chinese patients. The risk of hepatotoxicity increased significantly in CYP2E1 c1/c1 combined with rapid acetylator compared to slow acetylators indicating that CYP2E1 $\mathrm{c} 1 / \mathrm{c} 1$ is a biomarker independent of NAT status and CYP2E1 and NAT2 genotypes both contributed to the predisposition to INH DILI possibly through their roles in the production or detoxication of hepatoxic mediators (Huang et al., 2003). Consistent with this study, CYP2E1 c1/c1 was also associated with TB DILI in Tunisian (Ben Fredj et al., 2017) and Brazilian (Santos et al., 2013) patients. Nevertheless, there were some studies with different results. A study conducted in 2244 Xinjiang Uyghur TB patients found no association between CYP2E1 SNP and ALT elevation (Xiang et al., 2014). Besides, INH caused no liver injury in wild-type and CYP2E1-null mice suggesting that CYP2E1 may not involve in INH-induced hepatotoxicity (Cheng et al., 2013). Overall, the role of CYP2E1 genotype in INH-induced hepatotoxicity are controversial and further evidence is still needed.

Nearly $20 \%$ and $15 \%$ of patients developing INH-related liver toxicity have symptoms of fever or eosinophilia respectively, for which an immunological mechanism was speculated in INH-related liver injury. INH-peptide conducts were detected in vitro when INH was incubated with human liver microsomes which may result in liver injury in an immune allergic manner (Metushi et al., 2012). Furthermore, anti-INH antibodies and anti-P450 autoantibodies were detected in patients diagnosed with INH-induced liver failure providing solid evidence for an 
immune-related mechanism under INH -induced liver injury (Metushi et al., 2014). HLAII molecules are essential in the regulation of normal function of immune system and they are polymorphically expressed, SNPs of which may explain, to some extent, why an acute immune reaction was observed when rechallenged with INH. In North Indian patients $(n=346)$, absence of HLA-DQA $1 * 0102$ (OR 4.0) and presence of HLA-DQB $1 * 0201$ (OR 1.9) as risk factors were predictive in INH-induced hepatotoxicity (Sharma et al., 2002). Tumor necrosis factor alpha (TNF a), a cytotoxic cytokine produced by monocytes, is also involved in drug-induced immune reaction which mediates direct attack to hepatocytes. A TNF- $\alpha$ genetic polymorphism -308G/A was found significantly associated with anti-TB-induced hepatitis in Korean population (Kim et al., 2012).

MicroRNAs are also potential biomarkers for the early diagnosis of DILI including anti-TB-induced hepatotoxicity. MiR-122 could affect oxidative stress in mice and thus participating in INH-induced liver injury (Song et al., 2015). Furthermore, DNA methylation has been reported to regulate the expression level of miR-122, miR-125b, and miR-106b in rats during INH-induced liver injury (Li et al., 2018). Recently, the serum level of miR-122 and miR-192 in Indian subjects was measured. Compared to the healthy control, naive tuberculosis patients and anti-TB tolerant subjects, serum level of both miR-122 and miR-192 was decreased significantly in the DILI subjects (Bakshi et al., 2021), providing evidence for selecting microRNA as potential biomarkers for anti-TB-induced hepatotoxicity. However, studies on the clinical associations of microRNAs and DILI induced by anti-TB drugs are rarely reported, further investigations are needed. 


\subsection{Non-genetic biomarkers for anti-TB drug-induced liver injury}

There are few studies on non-genetic biomarkers for anti-TB agents related hepatotoxicity. INH as well as its conjugates with albumin could stimulate the lymphocyte transformation and patients whose lymphocyte transformation test was positive were more prone to suffer INH-induced hepatitis compared to negative subjects (Warrington et al., 1978; Warrington et al., 1982). An increased number of Th17 cells and T cells producing IL-10 was observed in 35 Canadian patients with mild liver injury who underwent INH prophylaxis treatment (Metushi et al., 2014). Peripheral blood mononuclear cells (PBMC) from 6 patients with anti-TB agent-related liver injury $(n=4)$ or skin adverse reaction $(\mathrm{n}=2)$ were all positive for lymphocyte transformation test and/or ELIspot. Besides, INH-specific $\mathrm{CD}^{+}{ }^{+} \mathrm{T}$-cell clones were identified in patients with liver and skin injury which suggests that the adaptive immune system is involved in INH-induced adverse event (Usui et al., 2017). In spite that these studies are based on small sample size, characterization of lymphocytes are reasonable to prevent severe liver injury when INH is rechallenged in patients whose immune system already develop immune memory. 


\section{Small molecular targeted anti-tumor drug-induced liver injury}

Tyrosine kinase inhibitors (TKIs) have improved survival dramatically in non-small cell lung cancer (NSCLC) patients carrying epidermal growth factor receptor (EGFR)-activating mutation and in breast cancer patients, including gefitinib, lapatinib, crizotinib, etc. TKIs associated DILI is the major concern in clinical practice with high prevalence, making it one of main reasons for drug discontinuation (Shah et al., 2013). In clinical trials, approximately $~ 60 \%$ patients developed TKIs-induced liver injury, $\sim 30 \%$ of which suffered grade $\geq 3$ DILI that led treatment interruption (Mitsudomi et al., 2010). Thus, several TKIs including lapatinib, gefitinib, pazopanib, regorafenib, crizotinib and sunitinib require routine monitor of liver function during treatment recommended by FDA box labels (https://www.accessdata.fda.gov/scripts/cder/daf/).

TKIs-induced liver injury is common and severe whereas the mechanism of DILI remains poorly investigated. It is assumed that CYPs polymorphisms are responsible for TKIs-induced liver injury since these mutations contribute to individual variations in pharmacokinetics, formation of reactive metabolites and further mediated immune dependent liver injury (Sugiyama et al., 2015; Paludetto et al., 2019). Most TKIs are mainly metabolized via CYP3A4, partially by CYP2C19 (gefitinib), CYP1A2 (erlotinib), CYP2C8 (lapatinib) and CYP2D6 (imatinib), implying that variants in CYPs are promising to predict TKI-induced liver injury (Hartmann et al., 2009). Meanwhile, TKIs exert vast individual variation in plasma exposure. For example, the median area under the concentration-time curve $\left(\mathrm{AUC}_{0-24}\right)$ was $10.086 \mu \mathrm{g} \cdot \mathrm{h} / \mathrm{mL}(3.247-24.726 \mu \mathrm{g} \cdot \mathrm{h} / \mathrm{mL})$ for gefitinib (Kobayashi et al., 2015), $79.518 \mu \mathrm{g} \cdot \mathrm{h} / \mathrm{mL}(34.665-182.409 \mu \mathrm{g} \cdot \mathrm{h} / \mathrm{mL}$ ) for lapatinib (Inoue et al., 2015) and the trough plasma concentration was $334 \mathrm{ng} / \mathrm{mL}(77.9-813 \mathrm{ng} / \mathrm{mL}$ ) for gefitinib (Kobayashi et al., 2015), $821 \mathrm{ng} / \mathrm{mL}$ (633-1064 ng/mL) for lapatinib (LaBonte et al., 
2016), respectively. Differences in drug exposure provide the rationale of identifying metabolomic biomarkers for DILI. In addition, recent publications reported distinct liver injury manner among different kinds of TKIs such as autophagy-dependent liver injury for gefitinib (Luo et al., 2020), mitochondrial toxicity for regorafenib (Akamine et al., 2015), crizotinib (Guo et al., 2021), and immune-mediated DILI for lapatinib (Spraggs et al., 2011), indicating that possible mechanistic biomarkers could be specific to each case (Table 5).

\subsection{Genetic markers for TKIs- induced liver injury}

As mentioned above, most TKIs are metabolized via CYPs. CYP polymorphisms could be potential predictors for TKIs-induced liver injury. Low activity of CYP2D6 could predict gefitinib-induced hepatotoxicity in several cases (Kijima et al., 2011). Another independent study validated this finding in a large cohort in Japanese (Sugiyama et al., 2015). These studies implied that gefitinib-induced liver injury is mediated by desmethyl-gefitinib, the main metabolite of gefitinib in plasma generated by CYP2D6 (McKillop et al., 2005). However, neither CYP2D6 variations nor exposure of desmethyl-gefitinib was found to be associated with gefitinib-induced liver injury (Kobayashi et al., 2016). In addition, a pharmacogenomics study showed that CYP2D6 polymorphisms was unrelated to gefitinib-induced liver injury, which was similar to $\mathrm{H}$. Kobayashi's finding (Kobayashi et al., 2015). Although FDA recommend to detect CYP2D6 polymorphisms before treatment, it fails to prevent patients from liver injury and large individual variation is still inevitable in clinical practice. Studies on the role of CYPs polymorphisms in both drug and metabolite exposure is in extreme shortage.

Since the chemical structure of TKIs vary a lot, the mechanism of liver injury could be 
idiosyncratic. An immune mechanism for lapatinib-induced liver injury in breast cancer patients was observed in a case-control study (Spraggs et al., 2011b). A two-stage (exploratory data set and confirmatory data set) pharmacogenetic investigation was conducted by genome-wide screening HLA polymorphisms within the major histocompatibility complex (MHC) in a retrospective study. The results showed that HLA-DQA1*02:01, TNXB rs12153855, HLA-DQB1*02:02, and HLA-DRB1*07:01 were associated with liver injury-induced by lapatinib. HLA-DQA1*02:01 allele was further validated as a clinically useful predictor of lapatinib-induced hepatotoxicity with negative predictive values of 0.97 and positive predictive values of 0.17 . Furthermore, Daniel J. Schaid and Colin F. Spraggs conducted a study to validate these MHC polymorphisms as predictors for hepatotoxicity of lapatinib in a prospective randomized controlled trial, and the results showed that HLA-DRB1*07:01 was a risk factor in lapatinib-induced liver injury (Schaid et al., 2014). More importantly, these results were introduced and validated in an international multi-centered clinical trial (Spraggs et al., 2018; Xiang et al., 2019; Tangamornsuksan et al., 2020). These findings imply that the underlying mechanism of lapatinib-induced hepatotoxicity is based on an immune-related pathology. The binding of the ligand peptide to HLA-DRB1*07:01, not HLA wild type, was supposed to be enhanced by lapatinib, which allowed the formation of a tightly closed binding groove structure thus stimulating the immune response leading to liver injury (Hirasawa et al., 2015). However, drug lymphocyte stimulation test was negative in lapatinib treated patients despite presence of HLA-DRB1*07:01 (Faulkner et al., 2016), challenging the assumption that lapatinib induced liver injury in an immune-related manner.

\subsection{Non-genetic markers for TKIs- induced liver injury}


The off-target effect of targeted drug is considered as one of the possible mechanisms for adverse reactions due to the physiological expression of target in normal tissues or organs, especially the liver. Thus, excess activity of the patent drug or generation of reactive metabolites may lead to hepatocytes damage and liver injury (Paludetto et al., 2019). Recently, the trough steady-state plasma concentration $(\mathrm{C} 0)$ of gefitinib was reported associated with gefitinib-induced liver injury in Japanese population and a cutoff of $334 \mathrm{ng} / \mathrm{mL}$ was determined with a satisfied sensitivity (82.4\%) and specificity (85.7\%) (Kobayashi et al., 2015). However, the results reported by Takashi Hirose et al., T. Kawamura et al. and our team revealed that neither the AUC nor the $\mathrm{C}_{0}$ of gefitinib correlated with gefitinib-induced hepatotoxicity (Xin et al., 2015; Hirose et al., 2016; Kawamura et al., 2020). Taken together, the relationship between gefitinib exposure in plasma and gefitinib-induced liver injury is still in controversy, large sample studies with appropriate subgroup analysis based on pharmacogenetics are needed in the future investigations.

Compared to the parent drug exposure, studies on the relationship between metabolites of TKIs and DILI are rare. The reactive aldehyde derivative is the toxic metabolite of sunitinib and pazopanib in vitro (Paludetto et al., 2018). These electrophilic metabolites were also successfully detected in plasma of several patients even though their roles in DILI were not fully studied (Paludetto et al., 2020). Meanwhile, using targeted metabolomics approach, we established a quantification method of plasma gefitinib and its four metabolites in NSCLC patients (Guan et al., 2019) and found that the exposures of metabolites were not associated with gefitinib-induced liver injury (data unpublished). Although several metabolites of TKIs could be detected by LC-MS/MS method, we still lack metabolite profiling method for the structure characterization of reactive metabolites of TKIs in vivo. 


\section{6. others}

As the prevalence of cardiovascular disease increases globally, cardiovascular drugs including antithrombotic, antihypertensive agents, antiarrhythmics and lipid-regulating agents are prescribed more often with a rising concern of cardiovascular drug-induced liver injury. The cardiovascular drug induced liver injury may not be fully observed during the clinical trials due to limited number of patients. However, the DILI may emerge after reaching the market with a large number of patients and long-term consumption of medicines. Cardiovascular drugs were the main group $(28.5 \%)$ leading to DILI $(9.8 \%)$ in a hepatotoxicity registry with a long-term follow-up study $(\mathrm{n}=$ 40) (Andrade et al., 2006) but most of the DILI cases were mild to moderate and rare of them developed to severe liver injury (Chalasani et al., 2004; Licata et al., 2018). Therefore, identifying clinical biomarkers for cardiovascular agents is extremely difficult due to relative rarity of incidences. Several researchers have concerned on clinical biomarkers for DILI induced by cardiovascular agents, we summarized these results in supplementary materials. 


\section{Discussion}

DILI is a highly complex process involved many factors such as host liver function, immune status, amount of drug exposure and so on. It tremendously and negatively influences the safety of medication and quality of patients' lives. Application of multi-omics technology and insights into pathophysiological mechanisms provide biomarkers like HLA polymorphisms, microRNAs, GLDH, HMGB1, mtDNA, certain lipids, etc. Compared to traditional biomarkers, these novel biomarkers appear to be more specific and sensitive in some extent. Nevertheless, there are some limitations of these biomarkers which remain a huge hurdle blocking their clinical translation.

First of all, rare incidence of severe DILI, racial and individual variations make it difficult for a candidate biomarker to be validated in limited population before application. Secondly, for genetic biomarkers, due to the low prevalence of mutations such as HLA SNPs for amoxicillin-clavulanate or lapatinib DILI, positive predictive value of routine test in clinic is disappointed. Finally, even though biomarkers indicated by mechanistic studies are promising, conclusions drawn from human subject-based validation studies often contradict to each other.

Definitely, studies on DILI biomarkers are insufficient and more effort should be involved to clarify DILIs and their specific biomarkers. These include i) application of advanced analytical methods and tools such as a deep machine learning for fully data mining; ii) international efforts and cooperation to identify and validate clinical biomarkers for DILI with rare incidence, i.e. Translational Safety Biomarker Pipeline, TransBioLine; iii) conduction of well-designed prospective DILI clinical studies for investigation of clinical biomarkers and so on. 


\section{Conflict of interest}

The authors declare that they have no conflict of interests.

\section{Acknowledgement}

This work was supported by Natural Science Foundation of China (No. 82025034, 81973392 and 81730103), the Shenzhen Science and Technology Program (No. KQTD20190929174023858), the National Key Research and Development Program (Grant: 2017YFE0109900, 2017YFC0909303), the 111 project (Grant: B16047), and the Guangdong Provincial Key Laboratory of Construction Foundation (No. 2017B030314030).

\section{Authorship Contributions}

Participated in research design and revised the manuscript: Huang and Bi

Performed data analysis: Chen and S.X. Guan

Wrote or contributed to the writing of the manuscript: Chen, S.X. Guan, Y.P. Guan, Tang, Zhou and Wang 


\section{References}

Abumiya M, Takahashi N, Niioka T, Kameoka Y, Fujishima N, Tagawa H, Sawada K, and Miura M (2014) Influence of UGT1A1 6, 27, and 28 polymorphisms on nilotinib-induced hyperbilirubinemia in Japanese patients with chronic myeloid leukemia. Drug Metab Pharmacokinet 29:449-454.

Akamine T, Ando K, Oki E, Saeki H, Nakashima Y, Imamura YU, Ohgaki K, and Maehara Y (2015) Acute Liver Failure Due to Regorafenib May Be Caused by Impaired Liver Blood Flow: A Case Report. Anticancer Res 35:4037-4041.

Alonso EM, James LP, Zhang S, Squires RH, and Pediatric Acute Liver Failure Study G (2015) Acetaminophen Adducts Detected in Serum of Pediatric Patients With Acute Liver Failure. $J$ Pediatr Gastroenterol Nutr 61:102-107.

Andrade RJ, Lucena MI, Fernandez MC, Pelaez G, Pachkoria K, Garcia-Ruiz E, Garcia-Munoz B, Gonzalez-Grande R, Pizarro A, Duran JA, Jimenez M, Rodrigo L, Romero-Gomez M, Navarro JM, Planas R, Costa J, Borras A, Soler A, Salmeron J, Martin-Vivaldi R, and Spanish Grp Study Drug-Induced L (2005) Drug-induced liver injury: An analysis of 461 incidences submitted to the Spanish Registry over a 10-year period. Gastroenterology 129:512-521.

Andrade RJ, Lucena MI, Kaplowitz N, Garcia-Munoz B, Borraz Y, Pachkoria K, Garcia-Cortes M, Fernandez MC, Pelaez G, Rodrigo L, Duran JA, Costa J, Planas R, Barriocanal A, Guarner C, Romero-Gomez M, Munoz-Yague T, Salmeron J, and Hidalgo R (2006) Outcome of acute idiosyncratic drug-induced liver injury: Long-term follow-up in a hepatotoxicity registry. Hepatology 44:1581-1588.

Andrade RJ, Robles M, Ulzurrun E, and Lucena MI (2009) Drug-induced liver injury: insights from 
genetic studies. Pharmacogenomics 10:1467-1487.

Andrade RJ, Chalasani N, Bjornsson ES, Suzuki A, Kullak-Ublick GA, Watkins PB, Devarbhavi H, Merz M, Lucena MI, Kaplowitz N, and Aithal GP (2019) Drug-induced liver injury. Nat Rev Dis Primers 5:58.

Andrews E, Armstrong M, Tugwood J, Swan D, Glaves P, Pirmohamed M, Aithal GP, Wright MC, Day CP, and Daly AK (2010) A role for the pregnane X receptor in flucloxacillin-induced liver injury. Hepatology 51:1656-1664.

Antoine DJ, Dear JW, Lewis PS, Platt V, Coyle J, Masson M, Thanacoody RH, Gray AJ, Webb DJ, Moggs JG, Bateman DN, Goldring CE, and Park BK (2013) Mechanistic biomarkers provide early and sensitive detection of acetaminophen-induced acute liver injury at first presentation to hospital. Hepatology 58:777-787.

Azuma J, Ohno M, Kubota R, Yokota S, Nagai T, Tsuyuguchi K, Okuda Y, Takashima T, Kamimura S, Fujio Y, Kawase I, and Pharmacogenetics-based tuberculosis therapy research g (2013) NAT2 genotype guided regimen reduces isoniazid-induced liver injury and early treatment failure in the 6-month four-drug standard treatment of tuberculosis: a randomized controlled trial for pharmacogenetics-based therapy. Eur J Clin Pharmacol 69:1091-1101.

Bakshi S, Kaur M, Saini N, Mir AA, Duseja A, Sinha SK, and Sharma S (2021) Altered expressions of circulating microRNAs 122 and 192 during antitubercular drug induced liver injury indicating their role as potential biomarkers. Hum Exp Toxicol 40:1474-1484.

Ben Fredj N, Gam R, Kerkni E, Chaabane A, Chadly Z, Boughattas N, and Aouam K (2017) Risk factors of isoniazid-induced hepatotoxicity in Tunisian tuberculosis patients. Pharmacogenomics $J$ 17:372-377. 
Bessone F (2010) Non-steroidal anti-inflammatory drugs: What is the actual risk of liver damage? World J Gastroenterol 16:5651-5661.

Bhattacharyya S, Yan K, Pence L, Simpson PM, Gill P, Letzig LG, Beger RD, Sullivan JE, Kearns GL, Reed MD, Marshall JD, Van Den Anker JN, and James LP (2014) Targeted liquid chromatography-mass spectrometry analysis of serum acylcarnitines in acetaminophen toxicity in children. Biomark Med 8:147-159.

Bins S, Lenting A, El Bouazzaoui S, van Doorn L, Oomen-de Hoop E, Eskens FA, van Schaik RH, and Mathijssen RH (2016) Polymorphisms in SLCO1B1 and UGT1A1 are associated with sorafenib-induced toxicity. Pharmacogenomics 17:1483-1490.

Bissada JE, Truong V, Abouda AA, Wines KJ, Crouch RD, and Jackson KD (2019) Interindividual Variation in CYP3A Activity Influences Lapatinib Bioactivation. Drug Metab Dispos 47:1257-1269.

Bjornsson E and Olsson R (2006) Suspected drug-induced liver fatalities reported to the WHO database. Dig Liver Dis 38:33-38.

Bjornsson ES (2016) Hepatotoxicity by Drugs: The Most Common Implicated Agents. Int J Mol Sci 17.

Bjornsson ES, Bergmann OM, Bjornsson HK, Kvaran RB, and Olafsson S (2013) Incidence, presentation, and outcomes in patients with drug-induced liver injury in the general population of Iceland. Gastroenterology 144:1419-1425, 1425 e1411-1413; quiz e1419-1420.

Boelsterli UA and Lee KK (2014) Mechanisms of isoniazid-induced idiosyncratic liver injury: emerging role of mitochondrial stress. J Gastroenterol Hepatol 29:678-687.

Bunchorntavakul C and Reddy KR (2013) Acetaminophen-related hepatotoxicity. Clin Liver Dis 
17:587-607, viii.

Chalasani N, Aljadhey H, Kesterson J, Murray MD, and Hall SD (2004) Patients with elevated liver enzymes are not at higher risk for statin hepatotoxicity. Gastroenterology 126:1287-1292.

Chalasani N, Bonkovsky HL, Fontana R, Lee W, Stolz A, Talwalkar J, Reddy KR, Watkins PB, Navarro V, Barnhart H, Gu J, Serrano J, and United States Drug Induced Liver Injury N (2015) Features and Outcomes of 899 Patients With Drug-Induced Liver Injury: The DILIN Prospective Study. Gastroenterology 148:1340-1352 e1347.

Chbili C, Hassine A, Fathallah N, Nouira M, Naija S, Ben Ammou S, and Saguem S (2018) Glutathione S-transferase M1 and T1 polymorphisms and the risk of mild hepatotoxicity induced by carbamazepine in a tunisian population study. BMC Neurol 18:24.

Chen Z-j, Wang X-d, Wang H-s, Chen S-d, Zhou L-m, Li J-l, Shu W-y, Zhou J-q, Fang Z-y, Zhang Y, and Huang M (2012) Simultaneous determination of valproic acid and 2-propyl-4-pentenoic acid for the prediction of clinical adverse effects in Chinese patients with epilepsy. Seizure 21:110-117.

Cheng J, Krausz KW, Li F, Ma X, and Gonzalez FJ (2013) CYP2E1-dependent elevation of serum cholesterol, triglycerides, and hepatic bile acids by isoniazid. Toxicol Appl Pharmacol $266: 245-253$

Chiew AL, James LP, Isbister GK, Pickering JW, McArdle K, Chan BSH, and Buckley NA (2020) Early acetaminophen-protein adducts predict hepatotoxicity following overdose (ATOM-5). $J$ Hepatol 72:450-462.

Court MH, Peter I, Hazarika S, Vasiadi M, Greenblatt DJ, Lee WM, and Acute Liver Failure Study G (2014) Candidate gene polymorphisms in patients with acetaminophen-induced acute liver 
failure. Drug Metab Dispos 42:28-32.

Court MH, Zhu Z, Masse G, Duan SX, James LP, Harmatz JS, and Greenblatt DJ (2017) Race, Gender, and Genetic Polymorphism Contribute to Variability in Acetaminophen Pharmacokinetics, Metabolism, and Protein-Adduct Concentrations in Healthy African-American and European-American Volunteers. J Pharmacol Exp Ther 362:431-440.

Cribb AE, Miller M, Leeder JS, Hill J, and Spielberg SP (1991) Reactions of the nitroso and hydroxylamine metabolites of sulfamethoxazole with reduced glutathione. Implications for idiosyncratic toxicity. Drug Metab Dispos 19:900-906.

Cribb AE and Spielberg SP (1992) Sulfamethoxazole is metabolized to the hydroxylamine in humans. Clin Pharmacol Ther 51:522-526.

Daly AK, Donaldson PT, Bhatnagar P, Shen Y, Pe'er I, Floratos A, Daly MJ, Goldstein DB, John S, Nelson MR, Graham J, Park BK, Dillon JF, Bernal W, Cordell HJ, Pirmohamed M, Aithal GP, Day CP, Study D, and International SAEC (2009) HLA-B*5701 genotype is a major determinant of drug-induced liver injury due to flucloxacillin. Nat Genet 41:816-819.

Danan G and Benichou C (1993) Causality assessment of adverse reactions to drugs--I. A novel method based on the conclusions of international consensus meetings: application to drug-induced liver injuries. J Clin Epidemiol 46:1323-1330.

Davern TJ, 2nd, James LP, Hinson JA, Polson J, Larson AM, Fontana RJ, Lalani E, Munoz S, Shakil AO, Lee WM, and Acute Liver Failure Study G (2006) Measurement of serum acetaminophen-protein adducts in patients with acute liver failure. Gastroenterology 130:687-694.

de Abajo FJ, Montero D, Madurga M, and García Rodríguez LA (2004) Acute and clinically relevant 
drug-induced liver injury: a population based case-control study. $\mathrm{Br}$ J Clin Pharmacol $58: 71-80$.

de Gage SB, Collin C, Thien L-T, Pariente A, Begaud B, Verdoux H, Dray-Spira R, and Zureik M (2018) Antidepressants and Hepatotoxicity: A Cohort Study among 5 Million Individuals Registered in the French National Health Insurance Database. CNS Drugs 32:673-684.

Dear JW, Clarke JI, Francis B, Allen L, Wraight J, Shen J, Dargan PI, Wood D, Cooper J, Thomas SHL, Jorgensen AL, Pirmohamed M, Park BK, and Antoine DJ (2018) Risk stratification after paracetamol overdose using mechanistic biomarkers: results from two prospective cohort studies. Lancet Gastroenterol Hepatol 3:104-113.

Devarbhavi H and Andrade RJ (2014) Drug-Induced Liver Injury Due to Antimicrobials, Central Nervous System Agents, and Nonsteroidal Anti-Inflammatory Drugs. Semin Liver Dis 34:145-161.

Faulkner L, Meng X, Naisbitt DJ, Spraggs CF, and Park BK (2016) No Evidence for Drug-Specific Activation of Circulating $\mathrm{T}$ Cells from Patients with HLA-DRB1*07:01-Restricted Lapatinib-Induced Liver Injury. Chem Res Toxicol 29:2111-2113.

Forrest JA, Clements JA, and Prescott LF (1982) Clinical pharmacokinetics of paracetamol. Clin Pharmacokinet 7:93-107.

Fukino K, Sasaki Y, Hirai S, Nakamura T, Hashimoto M, Yamagishi F, and Ueno K (2008) Effects of N-acetyltransferase 2 (NAT2), CYP2E1 and Glutathione-S-transferase (GST) genotypes on the serum concentrations of isoniazid and metabolites in tuberculosis patients. $J$ Toxicol Sci $33: 187-195$.

Fukushima Y, Seo T, Hashimoto N, Higa Y, Ishitsu T, and Nakagawa K (2008) 
Glutathione-S-transferase (GST) M1 null genotype and combined GSTM1 and GSTT1 null genotypes are risk factors for increased serum gamma-glutamyltransferase in valproic acid-treated patients. Clinica Chimica Acta 389:98-102.

Garcia-Cortes M, Stephens C, Lucena MI, Fernandez-Castaner A, and Andrade RJ (2011) Causality assessment methods in drug induced liver injury: strengths and weaknesses. J Hepatol $55: 683-691$.

Ghodke-Puranik Y, Thorn CF, Lamba JK, Leeder JS, Song W, Birnbaum AK, Altman RB, and Klein TE (2013) Valproic acid pathway: pharmacokinetics and pharmacodynamics. Pharmacogenet Genomics 23:236-241.

Ghozzi H, Hakim A, Sahnoun Z, Ben Mahmoud L, Atheymen R, Hammami S, and Zeghal K (2011) Relationship between plasma concentrations of valproic acid and hepatotoxicity in patients receiving high doses. Revue Neurologique 167:600-606.

Ginsberg G, Smolenski S, Hattis D, Guyton KZ, Johns DO, and Sonawane B (2009) Genetic Polymorphism in Glutathione Transferases (GST): Population distribution of GSTM1, T1, and P1 conjugating activity. J Toxicol Environ Health B Crit Rev 12:389-439.

Goda K, Saito K, Mute K, Kobayashi A, Saito Y, and Sugai S (2018) Ether-phosphatidylcholine characterized by consolidated plasma and liver lipidomics is a predictive biomarker for valproic acid-induced hepatic steatosis. J Toxicol Sci 43:395-405.

Goey AK, With M, Agema BC, Hoop EO, Singh RK, van der Veldt AA, Mathijssen RH, van Schaik RH, and Bins S (2019) Effects of pharmacogenetic variants on vemurafenib-related toxicities in patients with melanoma. Pharmacogenomics 20:1283-1290.

Grove JI and Aithal GP (2015) Human leukocyte antigen genetic risk factors of drug-induced liver 
toxicology. Expert Opin Drug Metab Toxicol 11:395-409.

Guan S, Chen X, Wang F, Xin S, Feng W, Zhu X, Liu S, Zhuang W, Zhou S, Huang M, Wang X, and Zhang L (2019) Development and validation of a sensitive LC-MS/MS method for determination of gefitinib and its major metabolites in human plasma and its application in non-small cell lung cancer patients. J Pharm Biomed Anal 172:364-371.

Guan SX CX, Huang M, Zhang L, Wang XD (2020) FOXO3 polymorphisms were correlated with gefitinib-induced hepatotoxicity in patients with non-small cell lung cancer. J Clin Oncol 38.

Guo H-L, Jing X, Sun J-Y, Hu Y-h, Xu Z-J, Ni M-M, Chen F, Lu X-P, Qiu J-C, and Wang T (2019) Valproic Acid and the Liver Injury in Patients with Epilepsy: An Update. Curr Pharm Des $25: 343-351$

Guo L, Gong H, Tang TL, Zhang BK, Zhang LY, and Yan M (2021) Crizotinib and Sunitinib Induce Hepatotoxicity and Mitochondrial Apoptosis in L02 Cells via ROS and Nrf2 Signaling Pathway. Front Pharmacol 12:620934.

Guo XG, Wang ZH, Dong W, He XD, Liu FC, and Liu H (2018) Specific CYP450 Genotypes in the Chinese Population Affect Sorafenib Toxicity in HBV/HCV-associated Hepatocellular Carcinoma Patients. Biomed Environ Sci 31:586-595.

Guo Y, Hu C, He X, Qiu F, and Zhao L (2012) Effects of UGT1A6, UGT2B7, and CYP2C9 Genotypes on Plasma Concentrations of Valproic Acid in Chinese Children with Epilepsy. Drug Metab Pharmacokinet 27:536-542.

Hartmann JT, Haap M, Kopp HG, and Lipp HP (2009) Tyrosine kinase inhibitors - a review on pharmacology, metabolism and side effects. Curr Drug Metab 10:470-481.

Hautekeete ML, Horsmans Y, Van Waeyenberge C, Demanet C, Henrion J, Verbist L, Brenard R, 
Sempoux C, Michielsen PP, Yap PS, Rahier J, and Geubel AP (1999) HLA association of amoxicillin-clavulanate--induced hepatitis. Gastroenterology 117:1181-1186.

Heard K, Green JL, Anderson V, Bucher-Bartelson B, and Dart RC (2016) Paracetamol (acetaminophen) protein adduct concentrations during therapeutic dosing. Br J Clin Pharmacol 81:562-568.

Heard KJ, Green JL, James LP, Judge BS, Zolot L, Rhyee S, and Dart RC (2011) Acetaminophen-cysteine adducts during therapeutic dosing and following overdose. BMC Gastroenterol 11:20.

Hein DW and Millner LM (2021) Arylamine N-acetyltransferase acetylation polymorphisms: paradigm for pharmacogenomic-guided therapy- a focused review. Expert Opin Drug Metab Toxicol $17: 9-21$

Henriksen JN, Bøttger P, Hermansen CK, Ladefoged SA, Nissen PH, Hamilton-Dutoit S, Fink TL, and Donskov F (2020) Pazopanib-Induced Liver Toxicity in Patients With Metastatic Renal Cell Carcinoma: Effect of UGT1A1 Polymorphism on Pazopanib Dose Reduction, Safety, and Patient Outcomes. Clin Genitourin Cancer 18:62-68.e62.

Hicks JK, Sangkuhl K, Swen JJ, Ellingrod VL, Muller DJ, Shimoda K, Bishop JR, Kharasch ED, Skaar TC, Gaedigk A, Dunnenberger HM, Klein TE, Caudle KE, and Stingl JC (2017) Clinical Pharmacogenetics Implementation Consortium Guideline (CPIC) for CYP2D6 and CYP2C19 Genotypes and Dosing of Tricyclic Antidepressants: 2016 Update. Clin Pharmacol Ther $102: 37-44$

Higuchi N, Tahara N, Yanagihara K, Fukushima K, Suyama N, Inoue Y, Miyazaki Y, Kobayashi T, Yoshiura K, Niikawa N, Wen CY, Isomoto H, Shikuwa S, Omagari K, Mizuta Y, Kohno S, and Tsukamoto K (2007) NAT2 6A, a haplotype of the N-acetyltransferase 2 gene, is an important 
biomarker for risk of anti-tuberculosis drug-induced hepatotoxicity in Japanese patients with tuberculosis. World J Gastroenterol 13:6003-6008.

Higuchi S, Yano A, Takai S, Tsuneyama K, Fukami T, Nakajima M, and Yokoi T (2012) Metabolic activation and inflammation reactions involved in carbamazepine-induced liver injury. Toxicol Sci 130:4-16.

Hirasawa M, Hagihara K, Okudaira N, and Izumi T (2015) The Possible Mechanism of Idiosyncratic Lapatinib-Induced Liver Injury in Patients Carrying Human Leukocyte Antigen-DRB1*07:01. Drug Metab Dispos 10:e0130928.

Hirose T, Fujita K, Kusumoto S, Oki Y, Murata Y, Sugiyama T, Ishida H, Shirai T, Nakashima M, Yamaoka T, Okuda K, Ohmori T, and Sasaki Y (2016) Association of pharmacokinetics and pharmacogenomics with safety and efficacy of gefitinib in patients with EGFR mutation positive advanced non-small cell lung cancer. Lung Cancer 93:69-76.

Ho PC, Abbott FS, Zanger UM, and Chang TKH (2003) Influence of CYP2C9 genotypes on the formation of a hepatotoxic metabolite of valproic acid in human liver microsomes. Pharmacogenomics J 3:335-342.

Huang YS, Chern HD, Su WJ, Wu JC, Chang SC, Chiang CH, Chang FY, and Lee SD (2003) Cytochrome P450 2E1 genotype and the susceptibility to antituberculosis drug-induced hepatitis. Hepatology 37:924-930.

Huang YS, Chern HD, Su WJ, Wu JC, Lai SL, Yang SY, Chang FY, and Lee SD (2002) Polymorphism of the $\mathrm{N}$-acetyltransferase 2 gene as a susceptibility risk factor for antituberculosis drug-induced hepatitis. Hepatology 35:883-889.

Huang YS, Su WJ, Huang YH, Chen CY, Chang FY, Lin HC, and Lee SD (2007) Genetic 
polymorphisms of manganese superoxide dismutase, NAD (P)H:quinone oxidoreductase, glutathione S-transferase M1 and T1, and the susceptibility to drug-induced liver injury. $J$ Hepatol 47:128-134.

Hung C-C, Ho J-L, Chang W-L, Tai JJ, Hsieh T-J, Hsieh Y-W, and Liou H-H (2011) Association of genetic variants in six candidate genes with valproic acid therapy optimization. Pharmacogenomics 12:1107-1117.

Huo T, Chen X, Lu X, Qu L, Liu Y, and Cai S (2014) An effective assessment of valproate sodium-induced hepatotoxicity with UPLC-MS and (HNMR)-H-1-based metabonomics approach. J Chromatogr B Analyt Technol Biomed Life Sci 969:109-116.

Hynynen J, Pokka T, Komulainen-Ebrahim J, Myllynen P, Karppa M, Pylvanen L, Kalviainen R, Sokka A, Jyrkila A, Lahdetie J, Haataja L, Makitalo A, Ylikotila P, Eriksson K, Haapala P, Ansakorpi H, Hinttala R, Vieira P, Majamaa K, Rantala H, and Uusimaa J (2018) Variants p.Q1236H and p.E1143G in mitochondrial DNA polymerase gamma POLG1 are not associated with increased risk for valproate-induced hepatotoxicity or pancreatic toxicity: A retrospective cohort study of patients with epilepsy. Epilepsia 59:2125-2136.

Inoue K, Kuroi K, Shimizu S, Rai Y, Aogi K, Masuda N, Nakayama T, Iwata H, Nishimura Y, Armour A, and Sasaki Y (2015) Safety, pharmacokinetics and efficacy findings in an open-label, single-arm study of weekly paclitaxel plus lapatinib as first-line therapy for Japanese women with HER2-positive metastatic breast cancer. Int J Clin Oncol 20:1102-1109.

James LP, Capparelli EV, Simpson PM, Letzig L, Roberts D, Hinson JA, Kearns GL, Blumer JL, Sullivan JE, Network of Pediatric Pharmacology Research Units NIoCH, and Human D (2008) Acetaminophen-associated hepatic injury: evaluation of acetaminophen protein adducts in 
children and adolescents with acetaminophen overdose. Clin Pharmacol Ther 84:684-690.

James LP, Letzig L, Simpson PM, Capparelli E, Roberts DW, Hinson JA, Davern TJ, and Lee WM (2009) Pharmacokinetics of acetaminophen-protein adducts in adults with acetaminophen overdose and acute liver failure. Drug Metab Dispos 37:1779-1784.

James LP, McGill MR, Roberts DW, Hinson JA, and Lee WM (2020) Advances in biomarker development in acetaminophen toxicity. Adv Clin Chem 98:35-50.

Ji Q, Shi X, Lin R, Mao Y, Zhai X, Lin Q, and Zhang J (2010) Participation of lipid transport and fatty acid metabolism in valproate sodium-induced hepatotoxicity in HepG2 cells. Toxicol In Vitro 24:1086-1091.

Kagawa T, Shirai Y, Oda S, and Yokoi T (2018) Identification of Specific MicroRNA Biomarkers in Early Stages of Hepatocellular Injury, Cholestasis, and Steatosis in Rats. Toxicol Sci $166: 228-239$.

Kampa JM, Sahin M, Slopianka M, Giampa M, Bednarz H, Ernst R, Riefke B, Niehaus K, and Fatangare A (2020) Mass spectrometry imaging reveals lipid upregulation and bile acid changes indicating amitriptyline induced steatosis in a rat model. Toxicol Lett 325:43-50.

Kawamura T, Imamura CK, Kenmotsu H, Taira T, Omori S, Nakashima K, Wakuda K, Ono A, Naito T, Murakami H, Mushiroda T, Takahashi T, and Tanigawara Y (2020) Evaluation of gefitinib systemic exposure in EGFR-mutated non-small cell lung cancer patients with gefitinib-induced severe hepatotoxicity. Cancer Chemother Pharmacol 85:605-614.

Kesterson JW, Granneman GR, and Machinist JM (1984) The hepatotoxicity of valproic acid and its metabolites in rats. I. Toxicologic, biochemical and histopathologic studies. Hepatology 4:1143-1152. 
Khandelwal N, James LP, Sanders C, Larson AM, Lee WM, and Acute Liver Failure Study G (2011) Unrecognized acetaminophen toxicity as a cause of indeterminate acute liver failure. Hepatology 53:567-576.

Kiang TKL, Abbott FS, Ho PC, and Chang TKH (2005) Contribution of CYP2C9, CYP2A6, and CYP2B6 to valproic acid metabolism in hepatic microsomes from individuals with the CYP2C9*1/*1 genotype. Toxicol Sci 19:A1112-A1112.

Kijima T, Shimizu T, Nonen S, Furukawa M, Otani Y, Minami T, Takahashi R, Hirata H, Nagatomo I, Takeda Y, Kida H, Goya S, Fujio Y, Azuma J, Tachibana I, and Kawase I (2011) Safe and successful treatment with erlotinib after gefitinib-induced hepatotoxicity: difference in metabolism as a possible mechanism. J Clin Oncol 29:e588-590.

Kim SH, Kim SH, Yoon HJ, Shin DH, Park SS, Kim YS, Park JS, and Jee YK (2012) TNF-alpha genetic polymorphism -308G/A and antituberculosis drug-induced hepatitis. Liver Int 32:809-814.

Kim SH, Saide K, Farrell J, Faulkner L, Tailor A, Ogese M, Daly AK, Pirmohamed M, Park BK, and Naisbitt DJ (2015) Characterization of amoxicillin- and clavulanic acid-specific $\mathrm{T}$ cells in patients with amoxicillin-clavulanate-induced liver injury. Hepatology 62:887-899.

Kobayashi H, Sato K, Niioka T, Miura H, Ito H, and Miura M (2015) Relationship Among Gefitinib Exposure, Polymorphisms of Its Metabolizing Enzymes and Transporters, and Side Effects in Japanese Patients With Non-Small-Cell Lung Cancer. Clin Lung Cancer 16:274-281.

Kobayashi H, Sato K, Niioka T, Takeda M, Okuda Y, Asano M, Ito H, and Miura M (2016) Effects of polymorphisms in CYP2D6 and ABC transporters and side effects induced by gefitinib on the pharmacokinetics of the gefitinib metabolite, O-desmethyl gefitinib. Med Oncol 33:57. 
Kurtovic J and Riordan SM (2003) Paracetamol-induced hepatotoxicity at recommended dosage. J Intern Med 253:240-243.

Kwon D, Kim SM, and Correia MA (2020) Cytochrome P450 endoplasmic reticulum-associated degradation (ERAD): therapeutic and pathophysiological implications. Acta Pharm Sin B $10: 42-60$.

LaBonte MJ, Yang D, Zhang W, Wilson PM, Nagarwala YM, Koch KM, Briner C, Kaneko T, Rha SY, Gladkov O, Urba SG, Sakaeva D, Pishvaian MJ, Hsieh RK, Lee WP, and Lenz HJ (2016) A Phase II Biomarker-Embedded Study of Lapatinib plus Capecitabine as First-line Therapy in Patients with Advanced or Metastatic Gastric Cancer. Mol Cancer Ther 15:2251-2258.

Lammert C, Einarsson S, Saha C, Niklasson A, Bjornsson E, and Chalasani N (2008) Relationship between daily dose of oral medications and idiosyncratic drug-induced liver injury: search for signals. Hepatology 47:2003-2009.

Larson AM (2007) Acetaminophen hepatotoxicity. Clin Liver Dis 11:525-548, vi.

Larson AM, Polson J, Fontana RJ, Davern TJ, Lalani E, Hynan LS, Reisch JS, Schiodt FV, Ostapowicz G, Shakil AO, Lee WM, and Acute Liver Failure Study G (2005) Acetaminophen-induced acute liver failure: results of a United States multicenter, prospective study. Hepatology 42:1364-1372.

Lauterburg BH, Smith CV, Todd EL, and Mitchell JR (1985) Pharmacokinetics of the toxic hydrazino metabolites formed from isoniazid in humans. J Pharmacol Exp Ther 235:566-570.

Lee J, Ji SC, Kim B, Yi S, Shin KH, Cho JY, Lim KS, Lee SH, Yoon SH, Chung JY, Yu KS, Park HS, Kim SH, and Jang IJ (2017) Exploration of Biomarkers for Amoxicillin/Clavulanate-Induced Liver Injury: Multi-Omics Approaches. Clin Transl Sci 10:163-171. 
Lee MS, Jung BH, Chung BC, Cho SH, Kim KY, Kwon OS, Nugraha B, and Lee Y-J (2009) Metabolomics Study With Gas Chromatography-Mass Spectrometry for Predicting Valproic Acid-induced Hepatotoxicity and Discovery of Novel Biomarkers in Rat Urine. Int J Toxicol 28:392-404.

Lee WM (2004) Acetaminophen and the U.S. Acute Liver Failure Study Group: lowering the risks of hepatic failure. Hepatology 40:6-9.

Lee WM (2017) Acetaminophen (APAP) hepatotoxicity-Isn't it time for APAP to go away? J Hepatol 67:1324-1331.

Li R, Qin X, Liang X, Liu M, and Zhang X (2019) Lipidomic characteristics and clinical findings of epileptic patients treated with valproic acid. J Cell Mol Med 23:6017-6023.

Li Y, Ren Q, Zhu L, Li Y, Li J, Zhang Y, Zheng G, Han T, Sun S, and Feng F (2018) Involvement of methylation of MicroRNA-122, $-125 \mathrm{~b}$ and $-106 \mathrm{~b}$ in regulation of Cyclin G1, CAT-1 and STAT3 target genes in isoniazid-induced liver injury. BMC Pharmacol Toxicol 19:11.

Licata A, Giammanco A, Minissale MG, Pagano S, Petta S, and Averna M (2018) Liver and Statins: A Critical Appraisal of the Evidence. Curr Med Chem 25:5835-5846.

Lin HJ, Han CY, Lin BK, and Hardy S (1994) Ethnic distribution of slow acetylator mutations in the polymorphic N-acetyltransferase (NAT2) gene. Pharmacogenetics 4:125-134.

Liu Y, Li P, Liu L, and Zhang Y (2018) The diagnostic role of miR-122 in drug-induced liver injury: A systematic review and meta-analysis. Medicine (Baltimore) 97:e13478.

Llewellyn HP, Vaidya VS, Wang Z, Peng Q, Hyde C, Potter D, Wang J, Zong Q, Arat S, Martin M, Masek-Hammerman K, Warner R, Johnson K, Kullak-Ublick GA, Aithal GP, Dear JW, and Ramaiah SK (2021) Evaluating the Sensitivity and Specificity of Promising Circulating 
Biomarkers to Diagnose Liver Injury in Humans. Toxicol Sci 181:23-34.

Lucena MI, Molokhia M, Shen Y, Urban TJ, Aithal GP, Andrade RJ, Day CP, Ruiz-Cabello F, Donaldson PT, Stephens C, Pirmohamed M, Romero-Gomez M, Navarro JM, Fontana RJ, Miller M, Groome M, Bondon-Guitton E, Conforti A, Stricker BH, Carvajal A, Ibanez L, Yue QY, Eichelbaum M, Floratos A, Pe'er I, Daly MJ, Goldstein DB, Dillon JF, Nelson MR, Watkins PB, Daly AK, Spanish DR, Eudragene, Dilin, Diligen, and International S (2011) Susceptibility to amoxicillin-clavulanate-induced liver injury is influenced by multiple HLA class I and II alleles. Gastroenterology 141:338-347.

Luo P, Yan H, Du J, Chen X, Shao J, Zhang Y, Xu Z, Jin Y, Lin N, Yang B, and He Q (2020) PLK1 (polo like kinase 1)-dependent autophagy facilitates gefitinib-induced hepatotoxicity by degrading COX6A1 (cytochrome c oxidase subunit 6A1). Autophagy:1-17.

Ma L, Pan Y, Sun M, Shen H, Zhao L, and Guo Y (2019) Catalase C-262T Polymorphism Is a Risk Factor for Valproic Acid-Induced Abnormal Liver Function in Chinese Patients With Epilepsy. Ther Drug Monit 41:91-96.

Maeda A, Ando H, Ura T, Komori A, Hasegawa A, Taniguchi H, Kadowaki S, Muro K, Tajika M, Kobara M, Matsuzaki M, Hashimoto N, Maeda M, Kojima Y, Aoki M, Kondo E, Mizutani A, and Fujimura A (2017) Association between ABCG2 and SLCO1B1 polymorphisms and adverse drug reactions to regorafenib: a preliminary study. Int J Clin Pharmacol Ther $55: 409-415$.

McCormack M, Alfirevic A, Bourgeois S, Farrell JJ, Kasperaviciute D, Carrington M, Sills GJ, Marson T, Jia X, de Bakker PI, Chinthapalli K, Molokhia M, Johnson MR, O'Connor GD, Chaila E, Alhusaini S, Shianna KV, Radtke RA, Heinzen EL, Walley N, Pandolfo M, Pichler W, Park 
BK, Depondt C, Sisodiya SM, Goldstein DB, Deloukas P, Delanty N, Cavalleri GL, and Pirmohamed M (2011) HLA-A*3101 and carbamazepine-induced hypersensitivity reactions in Europeans. N Engl J Med 364:1134-1143.

McGill MR (2016) The past and present of serum aminotransferases and the future of liver injury biomarkers. Excli j 15:817-828.

McGill MR, Li F, Sharpe MR, Williams CD, Curry SC, Ma X, and Jaeschke H (2014) Circulating acylcarnitines as biomarkers of mitochondrial dysfunction after acetaminophen overdose in mice and humans. Arch Toxicol 88:391-401.

McGill MR, Sharpe MR, Williams CD, Taha M, Curry SC, and Jaeschke H (2012) The mechanism underlying acetaminophen-induced hepatotoxicity in humans and mice involves mitochondrial damage and nuclear DNA fragmentation. J Clin Invest 122:1574-1583.

McGill MR, Staggs VS, Sharpe MR, Lee WM, Jaeschke H, and Acute Liver Failure Study G (2014) Serum mitochondrial biomarkers and damage-associated molecular patterns are higher in acetaminophen overdose patients with poor outcome. Hepatology 60:1336-1345.

McKillop D, McCormick AD, Millar A, Miles GS, Phillips PJ, and Hutchison M (2005) Cytochrome P450-dependent metabolism of gefitinib. Xenobiotica 35:39-50.

Metushi IG, Nakagawa T, and Uetrecht J (2012) Direct oxidation and covalent binding of isoniazid to rodent liver and human hepatic microsomes: humans are more like mice than rats. Chem Res Toxicol 25:2567-2576.

Metushi IG, Sanders C, Acute Liver Study G, Lee WM, and Uetrecht J (2014) Detection of anti-isoniazid and anti-cytochrome P450 antibodies in patients with isoniazid-induced liver failure. Hepatology 59:1084-1093. 
Metushi IG, Zhu X, Chen X, Gardam MA, and Uetrecht J (2014) Mild isoniazid-induced liver injury in humans is associated with an increase in Th17 cells and T cells producing IL-10. Chem Res Toxicol 27:683-689.

Meza-Junco J, Chu QS, Christensen O, Rajagopalan P, Das S, Stefanyschyn R, and Sawyer MB (2009) UGT1A1 polymorphism and hyperbilirubinemia in a patient who received sorafenib. Cancer Chemother Pharmacol 65:1-4.

Mico JA, Ardid D, Berrocoso E, and Eschalier A (2006) Antidepressants and pain. Trends in Pharmacoll Sci 27:348-354.

Mitsudomi T, Morita S, Yatabe Y, Negoro S, Okamoto I, Tsurutani J, Seto T, Satouchi M, Tada H, Hirashima T, Asami K, Katakami N, Takada M, Yoshioka H, Shibata K, Kudoh S, Shimizu E, Saito H, Toyooka S, Nakagawa K, and Fukuoka M (2010) Gefitinib versus cisplatin plus docetaxel in patients with non-small-cell lung cancer harbouring mutations of the epidermal growth factor receptor (WJTOG3405): an open label, randomised phase 3 trial. Lancet Oncol $11: 121-128$.

Molla Y, Wubetu M, and Dessie B (2021) Anti-Tuberculosis Drug Induced Hepatotoxicity and Associated Factors among Tuberculosis Patients at Selected Hospitals, Ethiopia. Hepat Med $13: 1-8$

Monshi MM, Faulkner L, Gibson A, Jenkins RE, Farrell J, Earnshaw CJ, Alfirevic A, Cederbrant K, Daly AK, French N, Pirmohamed M, Park BK, and Naisbitt DJ (2013) Human leukocyte antigen (HLA)-B*57:01-restricted activation of drug-specific $\mathrm{T}$ cells provides the immunological basis for flucloxacillin-induced liver injury. Hepatology 57:727-739.

Motzer RJ, Johnson T, Choueiri TK, Deen KC, Xue Z, Pandite LN, Carpenter C, and Xu CF (2013) 
Hyperbilirubinemia in pazopanib- or sunitinib-treated patients in COMPARZ is associated with UGT1A1 polymorphisms. Ann Oncol 24:2927-2928.

Nicoletti P, Aithal GP, Chamberlain TC, Coulthard S, Alshabeeb M, Grove JI, Andrade RJ, Bjornsson E, Dillon JF, Hallberg P, Lucena MI, Maitland-van der Zee AH, Martin JH, Molokhia M, Pirmohamed M, Wadelius M, Shen Y, Nelson MR, Daly AK, and International Drug-Induced Liver Injury C (2019) Drug-Induced Liver Injury due to Flucloxacillin: Relevance of Multiple Human Leukocyte Antigen Alleles. Clin Pharmacol Ther 106:245-253.

Nissen SE, Yeomans ND, Solomon DH, Luscher TF, Libby P, Husni ME, Graham DY, Borer JS, Wisniewski LM, Wolski KE, Wang Q, Menon V, Ruschitzka F, Gaffney M, Beckerman B, Berger MF, Bao W, Lincoff AM, and Investigators PT (2016) Cardiovascular Safety of Celecoxib, Naproxen, or Ibuprofen for Arthritis. N Engl J Med 375:2519-2529.

Paludetto MN, Bijani C, Puisset F, Bernardes-Génisson V, Arellano C, and Robert A (2018) Metalloporphyrin-Catalyzed Oxidation of Sunitinib and Pazopanib, Two Anticancer Tyrosine Kinase Inhibitors: Evidence for New Potentially Toxic Metabolites. J Med Chem 61:7849-7860.

Paludetto MN, Puisset F, Chatelut E, and Arellano C (2019) Identifying the reactive metabolites of tyrosine kinase inhibitors in a comprehensive approach: Implications for drug-drug interactions and hepatotoxicity. Med Res Rev 39:2105-2152.

Paludetto MN, Stigliani JL, Robert A, Bernardes-Génisson V, Chatelut E, Puisset F, and Arellano C (2020) Involvement of Pazopanib and Sunitinib Aldehyde Reactive Metabolites in Toxicity and Drug-Drug Interactions in Vitro and in Patient Samples. Chem Res Toxicol 33:181-190.

Perucca E (2002) Pharmacological and therapeutic properties of valproate - A summary after 35 years 
of clinical experience. CNS Drugs 16:695-714.

Price KE, Pearce RE, Garg UC, Heese BA, Smith LD, Sullivan JE, Kennedy MJ, Bale JF, Jr., Ward RM, Chang TKH, Abbott FS, and Leeder JS (2011) Effects of Valproic Acid on Organic Acid Metabolism in Children: A Metabolic Profiling Study. Clini Pharmacol Ther 89:867-874.

Ramachandran A and Jaeschke H (2017) Mechanisms of acetaminophen hepatotoxicity and their translation to the human pathophysiology. J Clin Transl Res 3:157-169.

Romoli M, Mazzocchetti P, D'Alonzo R, Siliquini S, Rinaldi VE, Verrotti A, Calabresi P, and Costa C (2019) Valproic Acid and Epilepsy: From Molecular Mechanisms to Clinical Evidences. Curr Neuropharmacol 17:926-946.

Roy B, Chowdhury A, Kundu S, Santra A, Dey B, Chakraborty M, and Majumder PP (2001) Increased risk of antituberculosis drug-induced hepatotoxicity in individuals with glutathione S-transferase M1 'null' mutation. J Gastroenterol Hepatol 16:1033-1037.

Rudorfer MV and Potter WZ (1999) Metabolism of tricyclic antidepressants. Cell Mol Neurobiol 19:373-409.

Sacco JC, Abouraya M, Motsinger-Reif A, Yale SH, McCarty CA, and Trepanier LA (2012) Evaluation of polymorphisms in the sulfonamide detoxification genes NAT2, CYB5A, and CYB5R3 in patients with sulfonamide hypersensitivity. Pharmacogenet Genomics 22:733-740.

Sacre A, Lanthier N, Dano H, Aydin S, Leggenhager D, Weber A, Dekairelle AF, De Cuyper A, Gala JL, Humblet Y, Sempoux C, and Van den Eynde M (2016) Regorafenib induced severe toxic hepatitis: characterization and discussion. Liver Int 36:1590-1594.

Sahini N, Selvaraj S, and Borlak J (2014) Whole Genome Transcript Profiling of Drug Induced Steatosis in Rats Reveals a Gene Signature Predictive of Outcome. PLoS One 9: e114085. 
Saif MW, Smith MH, Maloney A, and Diasio RB (2016) Imatinib-induced hyperbilirubinemia with UGT1A1 (*28) promoter polymorphism: first case series in patients with gastrointestinal stromal tumor. Ann Gastroenterol 29:551-556.

Saito K, Maekawa K, Ishikawa M, Senoo Y, Urata M, Murayama M, Nakatsu N, Yamada H, and Saito Y (2014) Glucosylceramide and Lysophosphatidylcholines as Potential Blood Biomarkers for Drug-Induced Hepatic Phospholipidosis. Toxicol Sci 141:377-386.

Saneto RP, Lee I-C, Koenig MK, Bao X, Weng S-W, Naviaux RK, and Wong L-JC (2010) POLG DNA testing as an emerging standard of care before instituting valproic acid therapy for pediatric seizure disorders. Seizure 19:140-146.

Santos EA, Goncalves JCS, Fleury MK, Kritski AL, Oliveira MM, Velasque LS, JRL ES, and Estrela RCE (2019) Relationship of anti-tuberculosis drug-induced liver injury and genetic polymorphisms in CYP2E1 and GST. Braz J Infect Dis 23:381-387.

Santos NP, Callegari-Jacques SM, Ribeiro Dos Santos AK, Silva CA, Vallinoto AC, Fernandes DC, de Carvalho DC, Santos SE, and Hutz MH (2013) N-acetyl transferase 2 and cytochrome P450 2E1 genes and isoniazid-induced hepatotoxicity in Brazilian patients. Int J Tuberc Lung Dis $17: 499-504$.

Saruwataria J, Deguchi M, Yoshimori Y, Noai M, Yoshida S, Ogusu N, Oniki K, Yoshida S, Yasui-Furukori N, Kaneko S, Ishitsu T, and Nakagawa K (2012) Superoxide dismutase 2 Val16Ala polymorphism is a risk factor for the valproic acid-related elevation of serum aminotransferases. Epilepsy Res 99:183-186.

Schaid DJ, Spraggs CF, McDonnell SK, Parham LR, Cox CJ, Ejlertsen B, Finkelstein DM, Rappold E, Curran J, Cardon LR, and Goss PE (2014) Prospective validation of HLA-DRB1*07:01 allele 
carriage as a predictive risk factor for lapatinib-induced liver injury. $J$ Clin Oncol 32:2296-2303.

Sgro C, Clinard F, Ouazir K, Chanay H, Allard C, Guilleminet C, Lenoir C, Lemoine A, and Hillon P (2002) Incidence of drug-induced hepatic injuries: a French population-based study. Hepatology 36:451-455.

Shah RR, Morganroth J, and Shah DR (2013) Hepatotoxicity of tyrosine kinase inhibitors: clinical and regulatory perspectives. Drug Saf 36:491-503.

Sharma SK, Balamurugan A, Saha PK, Pandey RM, and Mehra NK (2002) Evaluation of clinical and immunogenetic risk factors for the development of hepatotoxicity during antituberculosis treatment. Am J Respir Crit Care Med 166:916-919.

Shen T, Liu Y, Shang J, Xie Q, Li J, Yan M, Xu J, Niu J, Liu J, Watkins PB, Aithal GP, Andrade RJ, Dou X, Yao L, Lv F, Wang Q, Li Y, Zhou X, Zhang Y, Zong P, Wan B, Zou Z, Yang D, Nie Y, Li D, Wang Y, Han X, Zhuang H, Mao Y, and Chen C (2019) Incidence and Etiology of Drug-Induced Liver Injury in Mainland China. Gastroenterology 156:2230-2241.

Singh N, Dubey S, Chinnaraj S, Golani A, and Maitra A (2009) Study of NAT2 gene polymorphisms in an Indian population: association with plasma isoniazid concentration in a cohort of tuberculosis patients. Mol Diagn Ther 13:49-58.

Sitarz KS, Elliott HR, Karaman BS, Relton C, Chinnery PF, and Horvath R (2014) Valproic acid triggers increased mitochondrial biogenesis in POLG-deficient fibroblasts. Mol Genet Metab 112:57-63.

Song L, Zhang ZR, Zhang JL, Zhu XB, He L, Shi Z, Gao L, Li Y, Hu B, and Feng FM (2015) MicroRNA-122 is involved in oxidative stress in isoniazid-induced liver injury in mice. Genet 
Mol Res 14:13258-13265.

Spigset A, Hagg S, and Bate A (2003) Hepatic injury and pancreatitis during treatment with serotonin reuptake inhibitors: data from the World Health Organization (WHO) database of adverse drug reactions. Int Clin Psychopharmacol 18:157-161.

Spraggs CF, Budde LR, Briley LP, Bing N, Cox CJ, King KS, Whittaker JC, Mooser VE, Preston AJ, Stein SH, and Cardon LR (2011) HLA-DQA1*02:01 is a major risk factor for lapatinib-induced hepatotoxicity in women with advanced breast cancer. J Clin Oncol 29:667-673.

Spraggs CF, Parham LR, Briley LP, Warren L, Williams LS, Fraser DJ, Jiang Z, Aziz Z, Ahmed S, Demetriou G, Mehta A, Jackson N, Byrne J, Andersson M, Toi M, Harris L, Gralow J, Zujewski JA, Crescenzo R, Armour A, Perez E, and Piccart M (2018) Characterisation of the HLA-DRB1*07:01 biomarker for lapatinib-induced liver toxicity during treatment of early-stage breast cancer patients with lapatinib in combination with trastuzumab and/or taxanes. Pharmacogenomics $J$ 18:480-486.

Spraggs CF, Park BK, Spraggs CF, Budde LR, Briley LP, Bing N, Cox CJ, King KS, Whittaker JC, Mooser VE, Preston AJ, Stein SH, and Cardon LR (2011b) HLA-DQA1*02:01 is a major risk factor for lapatinib-induced hepatotoxicity in women with advanced breast cancer. Chem Res Toxicol 29:667-673.

Starkey Lewis PJ, Dear J, Platt V, Simpson KJ, Craig DG, Antoine DJ, French NS, Dhaun N, Webb DJ, Costello EM, Neoptolemos JP, Moggs J, Goldring CE, and Park BK (2011) Circulating microRNAs as potential markers of human drug-induced liver injury. Hepatology 54:1767-1776. 
Stewart JD, Horvath R, Baruffini E, Ferrero I, Bulst S, Watkins PB, Fontana RJ, Day CP, and Chinnery PF (2010) Polymerase gamma Gene POLG Determines the Risk of Sodium Valproate-Induced Liver Toxicity. Hepatology 52:1791-1796.

Stravitz RT and Lee WM (2019) Acute liver failure. Lancet 394:869-881.

Suenaga M, Schirripa M, Cao S, Zhang W, Yang D, Ning Y, Cremolini C, Antoniotti C, Borelli B, Mashima T, Okazaki S, Berger MD, Miyamoto Y, Gopez R, Jr., Barzi A, Lonardi S, Yamaguchi T, Falcone A, Loupakis F, and Lenz HJ (2018) Gene Polymorphisms in the CCL5/CCR5 Pathway as a Genetic Biomarker for Outcome and Hand-Foot Skin Reaction in Metastatic Colorectal Cancer Patients Treated With Regorafenib. Clin Colorectal Cancer 17:e395-e414.

Sugiyama E, Umemura S, Nomura S, Kirita K, Matsumoto S, Yoh K, Niho S, Ohmatsu H, Tsuboi M, Ohe Y, and Goto K (2015) Impact of single nucleotide polymorphisms on severe hepatotoxicity induced by EGFR tyrosine kinase inhibitors in patients with non-small cell lung cancer harboring EGFR mutations. Lung Cancer 90:307-313.

Sun J, Schnackenberg LK, Hansen DK, and Beger RD (2010) Study of valproic acid-induced endogenous and exogenous metabolite alterations using LC-MS-based metabolomics. Bioanalysis 2:207-216.

Tangamornsuksan W, Kongkaew C, Scholfield CN, Subongkot S, and Lohitnavy M (2020) HLA-DRB1*07:01 and lapatinib-induced hepatotoxicity: a systematic review and meta-analysis. 20:47-56.

Tate SK, Depondt C, Sisodiya SM, Cavalleri GL, Schorge S, Soranzo N, Thom M, Sen A, Shorvon SD, Sander JW, Wood NW, and Goldstein DB (2005) Genetic predictors of the maximum doses 
patients receive during clinical use of the anti-epileptic drugs carbamazepine and phenytoin. Proc Natl Acad Sci U S A 102:5507-5512.

Teschke R (2019) Idiosyncratic DILI: Analysis of 46,266 Cases Assessed for Causality by RUCAM and Published From 2014 to Early 2019. Front Pharmacol 10:730.

Teschke R and Danan G (2020) Worldwide Use of RUCAM for Causality Assessment in 81,856 Idiosyncratic DILI and 14,029 HILI Cases Published 1993-Mid 2020: A Comprehensive Analysis. Medicines (Basel) 7:62.

Tostmann A, Boeree MJ, Aarnoutse RE, de Lange WC, van der Ven AJ, and Dekhuijzen R (2008) Antituberculosis drug-induced hepatotoxicity: concise up-to-date review. J Gastroenterol Hepatol 23:192-202.

Ueda K, Ishitsu T, Seo T, Ueda N, Murata T, Hori M, and Nakagawa K (2007) Glutathione S-transferase M1 null genotype as a risk factor for carbamazepine-induced mild hepatotoxicity. Pharmacogenomics 8:435-442.

Usui T, Meng X, Saide K, Farrell J, Thomson P, Whitaker P, Watson J, French NS, Kevin Park B, and Naisbitt DJ (2017) From the Cover: Characterization of Isoniazid-Specific T-Cell Clones in Patients with anti-Tuberculosis Drug-Related Liver and Skin Injury. Toxicol Sci 155:420-431.

Vajda FJ, Drummer OH, Morris PM, McNeil JJ, and Bladin PF (1978) Gas chromatographic measurement of plasma levels of sodium valproate: tentative therapeutic range of a new anticonvulsant in the treatment of refractory epileptics. Clinical and experimental pharmacology \& physiology 5:67-73.

Vega M, Verma M, Beswick D, Bey S, Hossack J, Merriman N, Shah A, and Navarro V (2017) The Incidence of Drug- and Herbal and Dietary Supplement-Induced Liver Injury: Preliminary 
Findings from Gastroenterologist-Based Surveillance in the Population of the State of Delaware. Drug Saf 40:783-787.

Vliegenthart AD, Shaffer JM, Clarke JI, Peeters LE, Caporali A, Bateman DN, Wood DM, Dargan PI, Craig DG, Moore JK, Thompson AI, Henderson NC, Webb DJ, Sharkey J, Antoine DJ, Park BK, Bailey MA, Lader E, Simpson KJ, and Dear JW (2015) Comprehensive microRNA profiling in acetaminophen toxicity identifies novel circulating biomarkers for human liver and kidney injury. Sci Rep 5:15501.

Voican CS, Corruble E, Naveau S, and Perlemuter G (2014) Antidepressant-Induced Liver Injury: A Review for Clinicians. Am J Psychiatry 171:404-415.

Vukotic NT, Dordevic J, Pejic S, Dordevic N, and Pajovic SB (2021) Antidepressants- and antipsychotics-induced hepatotoxicity. Arch Toxicol 95:767-789.

Wang J, Bwayi M, Gee RRF, and Chen T (2020) PXR-mediated idiosyncratic drug-induced liver injury: mechanistic insights and targeting approaches. Expert Opin Drug Metab Toxicol 16:711-722.

Wang P, Pradhan K, Zhong XB, and Ma X (2016) Isoniazid metabolism and hepatotoxicity. Acta Pharm Sin B 6:384-392.

Ward J, Kanchagar C, Veksler-Lublinsky I, Lee RC, McGill MR, Jaeschke H, Curry SC, and Ambros VR (2014) Circulating microRNA profiles in human patients with acetaminophen hepatotoxicity or ischemic hepatitis. Proc Natl Acad Sci U S A 111:12169-12174.

Warrington RJ, McPhilips-Feener S, and Rutherford WJ (1982) The predictive value of the lymphocyte transformation test in isoniazid-associated hepatitis. Clin Allergy 12:217-222.

Warrington RJ, Tse KS, Gorski BA, Schwenk R, and Sehon AH (1978) Evaluation of isoniazid-associated hepatitis by immunological tests. Clin Exp Immunol 32:97-104. 
Weaver RJ, Betts C, Blomme EAG, Gerets HHJ, Gjervig Jensen K, Hewitt PG, Juhila S, Labbe G, Liguori MJ, Mesens N, Ogese MO, Persson M, Snoeys J, Stevens JL, Walker T, and Park BK (2017) Test systems in drug discovery for hazard identification and risk assessment of human drug-induced liver injury. Expert Opin Drug Metab Toxicol 13:767-782.

Wen B, Ma L, and Zhu M (2008) Bioactivation of the tricyclic antidepressant amitriptyline and its metabolite nortriptyline to arene oxide intermediates in human liver microsomes and recombinant P450s. Chem Biol Interact 173:59-67.

World Health Organization (2017) Guidelines for treatment of drug-susceptible tuberculosis and patient care.

Wolkenstein P, Carriere V, Charue D, Bastuji-Garin S, Revuz J, Roujeau JC, Beaune P, and Bagot M (1995) A slow acetylator genotype is a risk factor for sulphonamide-induced toxic epidermal necrolysis and Stevens-Johnson syndrome. Pharmacogenetics 5:255-258.

Woolbright BL and Jaeschke H (2017) Role of the inflammasome in acetaminophen-induced liver injury and acute liver failure. J Hepatol 66:836-848.

Xiang Q, Zhang Z, Wu Y, Zuo S, Liu Q, Liu T, Wang X, and Cui Y (2019) HLA Polymorphisms And TKI-Induced Liver Injury in Patients with Cancer: A Meta-analysis. J Cancer 10:2161-2168.

Xiang Y, Ma L, Wu W, Liu W, Li Y, Zhu X, Wang Q, Ma J, Cao M, Wang Q, Yao X, Yang L, Wubuli A, Merle C, Milligan P, Mao Y, Gu J, and Xin X (2014) The incidence of liver injury in Uyghur patients treated for TB in Xinjiang Uyghur autonomous region, China, and its association with hepatic enzyme polymorphisms nat2, cyp2e1, gstm1 and gstt1. PLoS One 9:e85905.

Xie HG, Xu ZH, Ou-Yang DS, Shu Y, Yang DL, Wang JS, Yan XD, Huang SL, Wang W, and Zhou HH (1997) Meta-analysis of phenotype and genotype of NAT2 deficiency in Chinese populations. 
Pharmacogenetics 7:503-514.

Xin S, Fang W, Li J, Li D, Wang C, Huang Q, Huang M, Zhuang W, Wang X, and Chen L (2021) Impact of STAT1 polymorphisms on crizotinib-induced hepatotoxicity in ALK-positive non-small cell lung cancer patients. J Cancer Res Clin Oncol 147:725-737.

Xin S, Zhao Y, Wang X, Huang Y, Zhang J, Guo Y, Li J, Li H, Ma Y, Chen L, Hu Z, Huang M, and Zhang L (2015) The Dissociation of Gefitinib Trough Concentration and Clinical Outcome in NSCLC Patients with EGFR Sensitive Mutations. Sci Rep 5:12675.

Xu S, Chen Y, Ma Y, Liu T, Zhao M, Wang Z, and Zhao L (2019) Lipidomic Profiling Reveals Disruption of Lipid Metabolism in Valproic Acid-Induced Hepatotoxicity. Frontiers in Pharmacol 10.

Yamada S, Tang M, Richardson K, Halaschek-Wiener J, Chan M, Cook VJ, Fitzgerald JM, Elwood RK, Brooks-Wilson A, and Marra F (2009) Genetic variations of NAT2 and CYP2E1 and isoniazid hepatotoxicity in a diverse population. Pharmacogenomics 10:1433-1445.

Yoo H, Chun Ji S, Cho JY, Kim SH, Yoon JG, Goo Lee M, Yu KS, Jang IJ, and Oh J (2021) A pilot study to investigate the utility of NAT2 genotype-guided isoniazid monotherapy regimens in NAT2 slow acetylators. Pharmacogenet Genomics 31:68-73.

Yoon E, Babar A, Choudhary M, Kutner M, and Pyrsopoulos N (2016) Acetaminophen-Induced Hepatotoxicity: a Comprehensive Update. J Clin Transl Hepatol 4:131-142.

Zaccara G, Franciotta D, and Perucca E (2007) Idiosyncratic adverse reactions to antiepileptic drugs. Epilepsia 48:1223-1244.

Zhao M, Zhang T, Li G, Qiu F, Sun Y, and Zhao L (2017) Associations of CYP2C9 and CYP2A6 Polymorphisms with the Concentrations of Valproate and its Hepatotoxin Metabolites and 
Valproate-Induced Hepatotoxicity. Basic Clin Pharmaco Toxicol 121:138-143.

Zielinska E, Niewiarowski W, Bodalski J, Rebowski G, Skretkowicz J, Mianowska K, and Sekulska M (1998) Genotyping of the arylamine N-acetyltransferase polymorphism in the prediction of idiosyncratic reactions to trimethoprim-sulfamethoxazole in infants. Pharm World Sci 20:123-130.

Zimmerman HJ (1968) The spectrum of hepatotoxicity. Perspect Biol Med 12:135-161.

Zimmerman HJ and Maddrey WC (1995) Acetaminophen (paracetamol) hepatotoxicity with regular intake of alcohol: analysis of instances of therapeutic misadventure. Hepatology 22:767-773. 


\section{Footnotes}

This work was supported by the National Natural Science Foundation of China [Grant 81730103, 82020108031, 81973398, 81473283 and 81573507]; The National Key Research and Development Program [Grant 2017YFC0909300 and 2016YFC0905000]; Guangdong Provincial Key Laboratory of Construction Foundation [Grant 2017B030314030]; Science and Technology Program of Guangzhou [Grant 201607020031]; National Engineering and Technology Research Center for New Drug Druggability Evaluation Seed Program of Guangdong Province [Grant 2017B090903004] and the 111 project [Grant B16047].

\section{Address correspondence to:}

Prof. Min Huang, Waihuan East Road No.132, Guangzhou Higher Education Mega Center, Guangzhou, China

E-mail: huangmin@mail.sysu.edu.cn

Prof. Huichang Bi, Waihuan East Road No.132, Guangzhou Higher Education Mega Center, Guangzhou, China

E-mail: bihchang@mail.sysu.edu.cn 


\section{Tables}

Table 1. Clinical biomarkers for AILI.

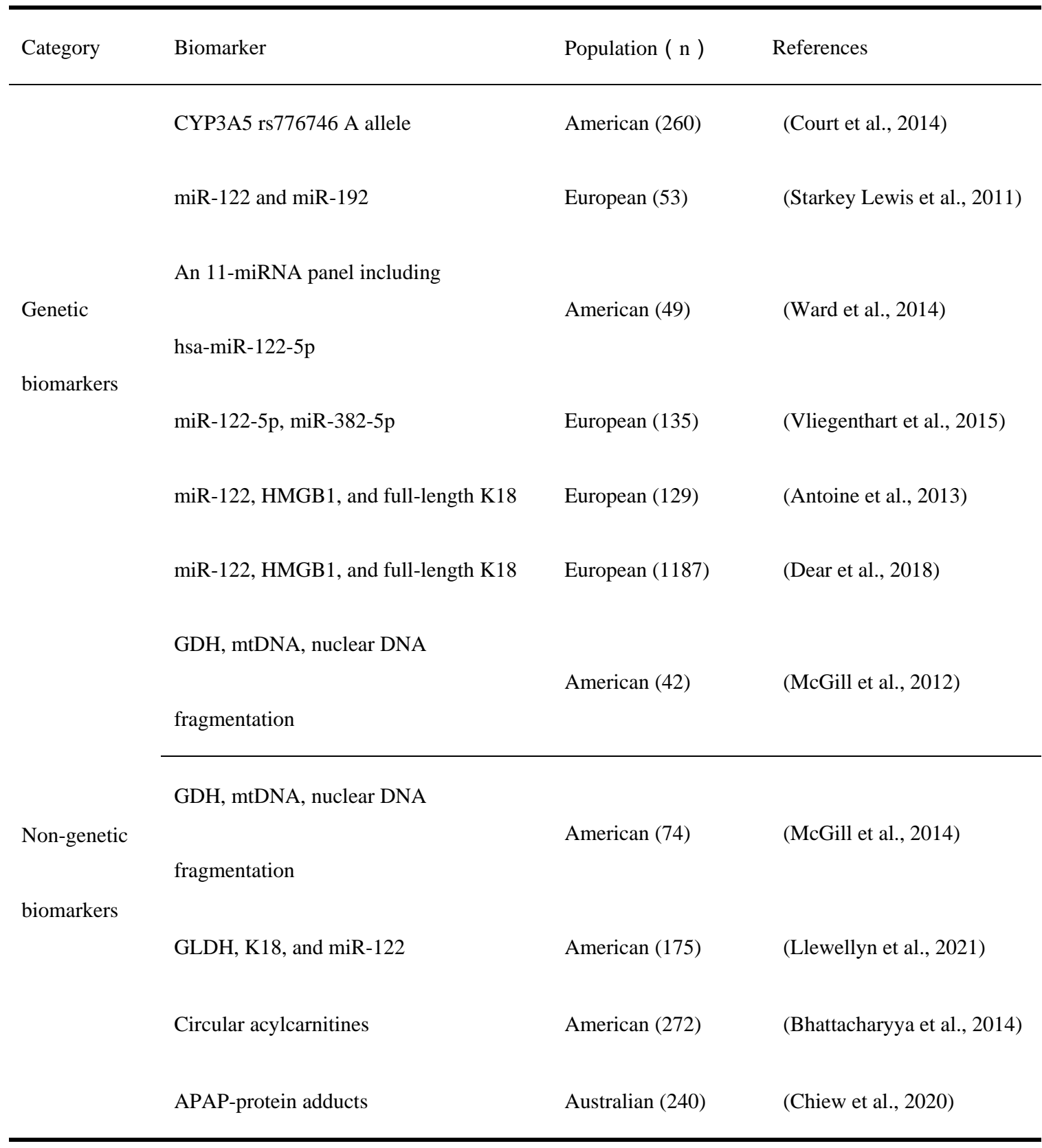


Table2. Clinical biomarkers for antiepileptic drug-induced liver injury.

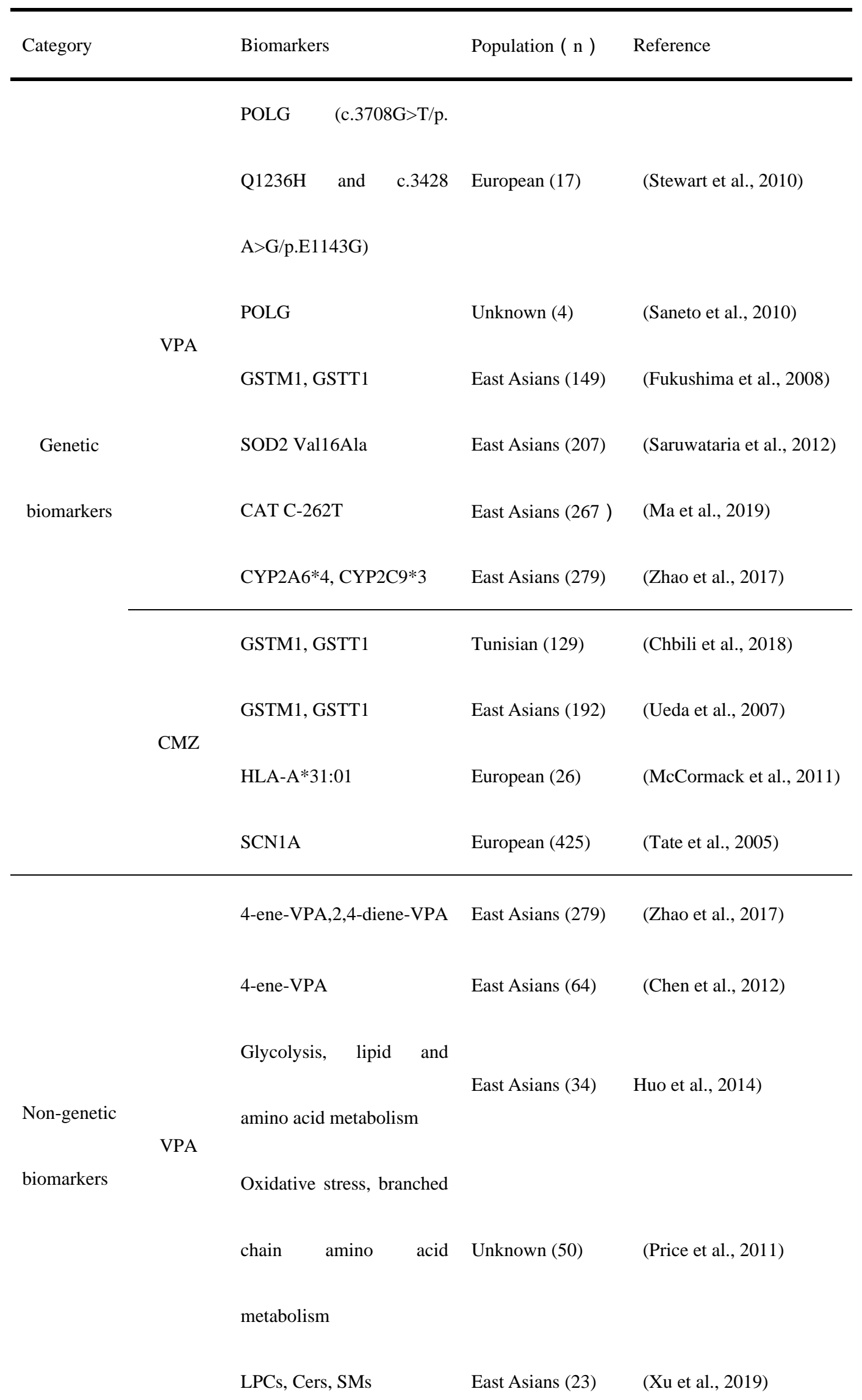


DMD Fast Forward. Published on December 13, 2021 as DOI: 10.1124/dmd.121.000732

This article has not been copyedited and formatted. The final version may differ from this version.

Lipid mediators $\quad$ East Asians (3) (Li et al., 2019)

CBZ plasma or 3-hydroxy

CMZ Unknown (Higuchi et al., 2012)

CBZ concentration 
Table 3. Clinical biomarkers for antimicrobial-induced liver injury.

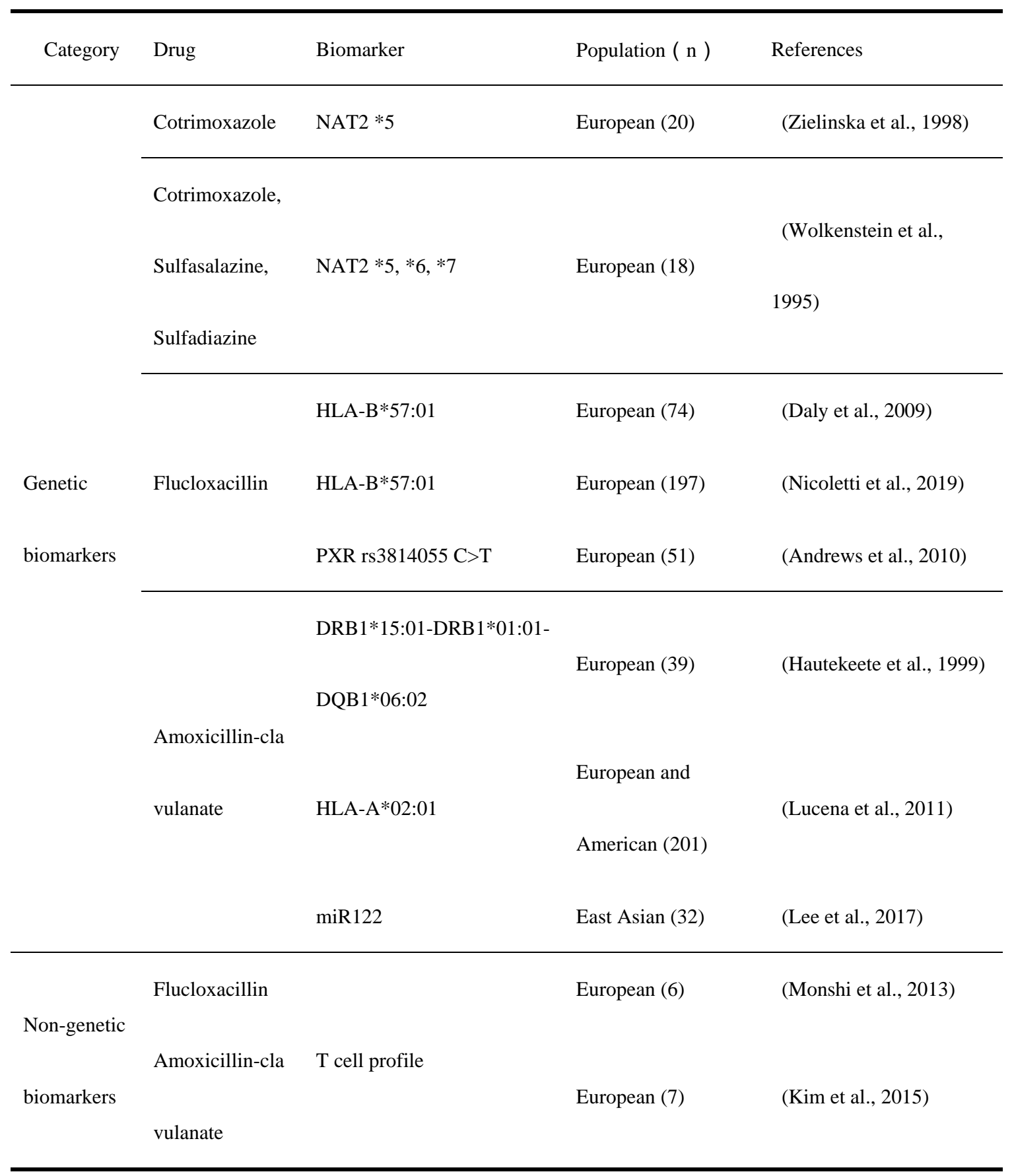


Table 4. Clinical biomarkers for anti-TB drug-induced liver injury.

\begin{tabular}{|c|c|c|c|c|}
\hline Category & Drug & Biomarker & Population (n) & Reference \\
\hline \multirow{20}{*}{$\begin{array}{l}\text { Genetic } \\
\text { biomarkers }\end{array}$} & \multirow{13}{*}{ INH } & NAT $2 * 5, * 6, * 7$ & East Asian (224) & (Huang et al., 2002) \\
\hline & & NAT2 $* 6 A$ & East Asian (100) & (Higuchi et al., 2007) \\
\hline & & $\mathrm{NAT} 2 * 5 \mathrm{~B}, * 6 \mathrm{~A}$ & South Asian (201) & (Singh et al., 2009) \\
\hline & & & East Asian (318) & (Huang et al., 2003) \\
\hline & & CYP2E1 c1/c1, NAT2 & & \\
\hline & & & African (71) & (Ben Fredj et al., 2017) \\
\hline & & $* 5 * 6 * 7$ & & \\
\hline & & & South American (270) & (Santos et al., 2013) \\
\hline & & Absence of & \multirow{5}{*}{ South Asian (346) } & \multirow{5}{*}{ (Sharma et al., 2002) } \\
\hline & & HLA-DQA1*0102, & & \\
\hline & & & & \\
\hline & & presence of & & \\
\hline & & HLA-DQB1*0201 & & \\
\hline & \multirow{7}{*}{ Combination } & GSTM1 null & South Asian (33) & (Roy et al., 2001) \\
\hline & & GSTM1 null & East Asian (63) & (Huang et al., 2007) \\
\hline & & & & \\
\hline & & GSTT1 null, CYP2E1 & & \\
\hline & & & South American (43) & (Santos et al., 2019) \\
\hline & & $\mathrm{c} 1 / \mathrm{c} 1$ & & \\
\hline & & MiR-122, miR-192 & South Asian (50) & (Bakshi et al., 2021) \\
\hline \multirow{4}{*}{ Non-genetic } & & Th17 and T cell & \multirow{3}{*}{ Canadian (35) } & \multirow{4}{*}{ (Metushi et al., 2014) } \\
\hline & & & & \\
\hline & & expressing IL-10 & & \\
\hline & INH & & & \\
\hline \multirow[t]{3}{*}{ biomarkers } & & Isoniazid-specific CD4+ & \multirow{3}{*}{ Caucasians (5) } & \multirow{3}{*}{ (Usui et al., 2017) } \\
\hline & & & & \\
\hline & & T-cell & & \\
\hline
\end{tabular}

${ }^{\mathrm{f}}$ Combination therapy = Isoniazid, rifampicin, pyrazinamide, and ethambutol 
Table 5. Genetic biomarkers for TKI-induced liver injury.

\begin{tabular}{|c|c|c|c|c|}
\hline Drug & Cancer type ${ }^{f}$ & Biomarker & Population (n) & References \\
\hline Erlotinib & NSCLC & CYP2D6 $* 5$ or $* 10$ & East Asians (25) & (Kobayashi et al., 2015) \\
\hline \multirow{3}{*}{ Gefitinib } & NSCLC & CYP 3 A $5 * 3 / * 3$ & East Asians (60) & (Sugiyama et al., 2015) \\
\hline & & & & \\
\hline & NSCLC & FOXO3 rs75544369/rs4946935 & East Asians (172) & (Guan SX, 2020) \\
\hline Crizotinib & NSCLC & STAT1 rs10208033 & East Asians (42) & (Xin et al., 2021) \\
\hline Imatinib & CML/GIST & UGT1A $1 * 28$ & Caucasians (2) & (Saif et al., 2016) \\
\hline \multirow{3}{*}{ Lapatinib } & $\mathrm{mBC}$ & CYP3A5 *3 & Global (12) & (Bissada et al., 2019) \\
\hline & & & & \\
\hline & $\mathrm{mBC}$ & HLA-DQA1 *02:01 & Caucasians (24) & (Spraggs et al., 2011) \\
\hline \multirow[t]{2}{*}{ Nilotinib } & CML & UGT1A $1 * 6 / * 6, * 6 / * 28$ & East Asians (34) & (Abumiya et al., 2014) \\
\hline & $\mathrm{mRCC}$ & UGT1A1 $* 28$ & Caucasians (261) & (Henriksen et al., 2020) \\
\hline \multicolumn{5}{|l|}{ Pazopanib } \\
\hline & $\mathrm{mRCC}$ & UGT1A $1 * 36, * 37$ or $* 6$ & Global (62) & (Motzer et al., 2013) \\
\hline \multirow{6}{*}{ Regorafenib } & $\mathrm{mCRC}$ & UGT1A9 $* 22$ & Caucasians (3) & (Sacre et al., 2016) \\
\hline & Unknown & $\mathrm{SLCO} 1 \mathrm{~B} 1 * 1 \mathrm{~b}$ & East Asians (37) & (Maeda et al., 2017) \\
\hline & $\mathrm{mCRC}$ & CCL3 rs1130371 & East Asians (79) & \\
\hline & & & and Caucasians & (Suenaga et al., 2018) \\
\hline & $\mathrm{mCRC}$ & CCL4 rs1634517 & & \\
\hline & & & $(150)$ & \\
\hline \multirow[t]{2}{*}{ Sunitinib } & $\mathrm{RCC}$ & UGT1A $1 * 28, * 37$ or $* 6$ & Global (246) & (Motzer et al., 2013) \\
\hline & Melanoma & CYP3A4 *22 & & \\
\hline \multirow[t]{3}{*}{ Vemurafenib } & & & Caucasians (97) & (Goey et al., 2019) \\
\hline & Melanoma & $\mathrm{ABCB} 13435 \mathrm{C}>\mathrm{T}$ & & \\
\hline & Unknown & $\mathrm{SLCO} 1 \mathrm{~B} 1 * 1 \mathrm{~b}$ & Caucasians (114) & (Bins et al., 2016) \\
\hline \multicolumn{5}{|l|}{ Sorafenib } \\
\hline & $\mathrm{HCC}$ & UGT1A1 $* 28$ & Caucasians (1) & (Meza-Junco et al., 2009) \\
\hline
\end{tabular}


${ }^{\mathrm{f}} \mathrm{CML}=$ chronic myeloid leukemia; GIST=gastrointestinal stromal tumor; $\mathrm{mBC}=$ metastatic breast cancer; $\mathrm{mRCC}=$ metastatic renal cell carcinoma; $\mathrm{mCRC}=$ metastatic colorectal cancer; $\mathrm{RCC}=$ renal cell carcinoma; $\mathrm{HCC}=$ hepatocellular carcinoma 